\title{
Composition variation of the essential oil from Ocimum basilicum L. cv. Genovese Gigante in response to Glomus intraradices and mild water stress at different stages of growth
}

\author{
Iris Mota ${ }^{\mathrm{a}, *}$, José Sánchez-Sánchez ${ }^{\mathrm{a}}$, Luis G. Pedro ${ }^{\mathrm{b}}$, Maria João Sousa ${ }^{\mathrm{c}}$ \\ ${ }^{a}$ Centro Hispano-Luso de Investigaciones Agrarias (C.I.A.L.E.), Universidad de Salamanca, Río Duero-12, Villamayor, 37185, Salamanca, Spain \\ ${ }^{\mathrm{b}}$ Centro de Estudos Do Ambiente e Do Mar (CESAM Lisboa), Faculdade de Ciências da Universidade de Lisboa, Centro de Biotecnologia Vegetal (CBV), Edifício C2, Campo \\ Grande, 1749-016, Lisboa, Portugal

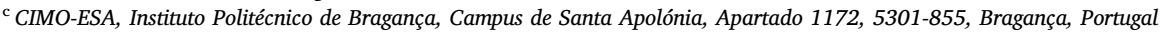

\section{A R T I C L E I N F O}

\section{Keywords:}

Secondary metabolism

Arbuscular mycorrhizal fungi

Phenylpropanoids

Terpenes

Abiotic stress

Ontogeny

\begin{abstract}
In this study, a factorial experiment was carried out to investigate the effect of AMF (arbuscular mycorrhizal fungi) and water stress on the quality of fresh plants (through the analysis of essential oil composition) and also on the morphological characteristics (in terms of biomass) of basil (Ocimum basilicum L. cv. Genovese Gigante). The factors included an arbuscular mycorrhizal fungus inoculation (Glomus intraradices), irrigation level (mild water stress, $60 \%$ Field capacity) and the interaction of both AMF and water stress. In addition, the effects of harvesting at two different developmental stages were assessed with respect to the plants tolerance to abiotic stress and the quality of the fresh plant. The main essential oil (EO) constituents for this cultivar were eugenol, which varied between 7.1 and 50.8\%, and linalool, 17.0-54.7\%, in all the samples. The highest relative amount of eugenol (50.8\%) was obtained during the vegetative stage in plants under water stress whereas samples from the control presented $16.2 \%$ for this compound. The samples which were significantly different from the control samples were the WS (water stress) samples from the vegetative stage. Additionally, this study suggests that AMF plants offset the adverse effect of water stress. In this context, and since the interaction of AMF and water stress did not significantly change the fresh plant quality, i.e. the essential oil profile in both stages of development, it is worthwhile considering this method of production. Finally, this experiment permitted an understanding of the stressor thresholds of the species used and also that, compensatory responses occur at different time scales, including between generations and also during development (developmental plasticity).
\end{abstract}

Abstract

\section{Introduction}

Nowadays, faced with the reality of climate change and the increasing threat of unstable precipitation and temperature increase in certain parts of the globe, there is a need to find new methods of cultivation of crops and medicinal and aromatic plants (MAP). The exploitation of water is therefore particularly important in arid or semiarid climates, such as that of the Mediterranean.

One of the various parameters used to understand plant adaptation with regards to a specific environmental factor (abiotic or biotic) is through the analysis of volatile emissions. Terpenoids, which form the largest class of secondary (or specialized) metabolites in plants (Lange and Srividya, 2018) can be used to understand plant plasticity. Indeed, in the literature an attempt is made to refine ecological perspectives on plant behavior by focusing explicitly on secondary metabolites which plants produce rapidly to respond to and manipulate their abiotic and biotic environments (Metlen et al., 2009). Furthermore, it has been described that if the abiotic and biotic factors undermine the 'healthy state' of the plant there is so-called de novo production, i.e. when compounds are produced in greater quantity and/or in a different ratio (as opposed to constitutive production) (Figueiredo et al., 2008).

In a Mediterranean climate scenario, where plants are subjected to water stress (which seems to be associated with the rise of essential oil production in certain species), about $38 \%$ of the species are essential oil-bearing plants, whereas in tropical climates, this number decreases to $11 \%$ (Figueiredo et al., 2008). However, under water stress, it is

\footnotetext{
* Corresponding author.

E-mail addresses: id00726040@usal.es (I. Mota), jss@usal.es (J. Sánchez-Sánchez), lmpedro@fc.ul.pt (L.G. Pedro), joaos@ipb.pt (M.J. Sousa).
} 
common to observe a detrimental effect in terms of plant biomass. Thus, the reactions of plants to water stress differ significantly at various organizational levels depending on the intensity and duration of stress as well as the plant species and its stage of growth (Chaves et al., 2002). One approach to counteract the negative effects of water stress could be to use an allegedly arbuscular mycorrhizal fungi (AMF), which is a biofertilizer and bioprotectant (Xavier and Boyetchko, 2002). Indeed, the alleviating effect of AMF symbiosis in response to drought generally relies on the positive effects of mycorrhizae on the uptake and transport of water and on an improved uptake of nutrients, especially of available soil phosphorus $(\mathrm{P})$ and other immobile mineral nutrients, which results in a clear promotion of growth (Augé, 2001). Nonetheless, certain AMF genotypes possess different functionalities in affecting host plants, including the spread of extraradical mycelia, efficiency of nutrient absorption, and mycorrhizal-specific gene expression, and they cause different growth responses in host plants (Lee et al., 2013). The AMF species used in this experiment is considered to be a generalist (Oehl et al., 2010) and is one of the most commonly studied AMF species due to its ability to colonize host plants rapidly (Martin et al., 2008). In addition to its rapid colonization, it is a widespread fungal species, due to the fact that it is present in different ecosystems throughout the world, including both temperate and tropical locations (Smith and Read, 2008). Fungi which are rapid colonists appear to generate the greatest growth benefits in low-P-fertility soils, and the greatest growth depressions in highly-fertilized soils (Abbott and Robson, 1985), which leads us to define AMF as 'cheaters', as, instead of determining greater plant biomass and flowering, the mycorrhiza reduces the growth of the host plant (Johnson et al., 1997). It is important to account for these variations, as the parasitism-mutualism continuum has been broadly described for different AMF species. Accordingly, efficient root colonization and rhizosphere competences are both fundamental factors in establishing the beneficial effects and the success of AMF inoculation in plant growth (Bharti et al., 2016), and subsequently, the plasticity of plant responses to abiotic factors.

A great many studies in the literature test the effect of arbuscular mycorrhizal fungi or water deficit in MAP, and a lesser amount examine the interaction of both according to Jayne and Quigley (2014). However, over the past five years, more papers have been published on the interaction of both factors on crops and MAP (Sun et al., 2017; Huang et al., 2017; Gheisari et al., 2017; Polcyn et al., 2019). A major goal of most studies examining water and mycorrhizal colonization is to improve the overall performance of plants with agricultural and horticultural importance, such as basil (Copetta et al., 2006; Hazzoumi et al., 2017). However, according to Miller et al. (2014), the vast majority of studies which test phenotypic theories and document changes in chemical defenses in response to environmental variation compare plants which are grown under different conditions at a common time/age. Same-age comparisons can therefore obscure both the developmental basis of a defense phenotype as well as true phenotypic plasticity in response to environmental variability (Miller et al., 2014). As such, two growth stages were chosen in our study since ontogeny modifies the response of crop growth and water use to drought throughout the growing season (Winkel et al., 2001), which consequently can affect secondary metabolite biosynthesis and plant-mycorrhizal interactions (Ronsheim, 2012). According to Barton and Boege (2017), most studies on the evolutionary ecology of plant defense have concentrated their efforts on particular plant ontogenetic stages, offering important, albeit partial, information or snapshots of the selective dynamics that influence the evolution of plant defense. For this reason, the selective dynamics influencing the evolution of plant defense due to different (but not particular) plant ontogenetic stages are important in order to gain a clear idea of which factors are responsible for driving the evolution of defense/stress response patterns.

Since the emphasis in the literature on the effect of mycorrhizal colonization on plant growth or secondary metabolite biosynthesis with the application of water stress or other abiotic factors effects has been mainly on short-termed experiments, we are of the opinion that in this experiment much more can be learned if interactions between water stress levels and mycorrhizal colonization were studied, using a larger time-scale into account with two growth stages. Keeping this in view, the present study was carried out to investigate the effects of mild water stress (60\% of Field capacity) on plant growth and the chemical profile of essential oils and also to evaluate the role of an arbuscular mycorrhizal fungus (Glomus intraradices) in mitigating the water stress effects and their possible influence on the chemical profile of the essential oil and fresh plant quality of Ocimum basilicum L. cv. Genovese Gigante (Genovese Gigante basil). The latter tests seem pertinent, as there is a rapid growth nowadays in the production of fresh herbs and EOs in response to increasing consumer demand (Havkin-Frenkel and Dudai, 2016; Chouhan et al., 2017).

\section{Materials and methods}

\subsection{Experimental design}

A 4x6 factorial randomized complete block design was carried out in a greenhouse of the Hispano-Luso Agrarian Research Center (C.I.A.L.E.), Department of Botany in Salamanca, Spain, between October 2017-April 2018, under natural conditions of light with controlled temperature $\left(26^{\circ} \mathrm{C} \pm 5{ }^{\circ} \mathrm{C}\right)$ and an humidity range of $45-50 \%$. In addition, a QSO-S photon flux sensor (Decaegon Devices, Inc., USA) was positioned in the plants glasshouse bench to measure the photosynthetic photon flux (PPF) in $\mu \mathrm{mol} \mathrm{m} \mathrm{m}^{-2} \mathrm{~s}^{-1}$. The PPF was recorded every minute using an EM50 digital data logger (Decaegon Devices, Inc., USA). Posteriorly, the data were acquired using the 'ECHO2 utility' software. Seeds were obtained from the C.I.A.L.E germplasm bank. The design consisted of two mycorrhizal conditions: inoculated or non-inoculated with an arbuscular mycorrhizal fungus (G. intraradices) combined with two levels of water regime, either $60 \%$ of Field capacity (FC) or $100 \%$ FC. The different treatments were categorised as: Water Stress (WS), Mycorrhizae (M) and Water stress x Mycorrhizae (WSxM). Noninoculated plants, as well as those not submitted to water stress were used as the Control (C). Furthermore, the pots were shifted weekly on the greenhouse bench to control for any differences in light conditions.

Seeds were surface sterilized with a hypochlorite solution at $10 \%$ for $5 \mathrm{~min}$. After $5 \mathrm{~min}$ the solution was removed, and distilled water was added. Afterwards, all the water was removed, and the seeds were placed on agar-agar petri dishes which were pulverized 2 to 3 times with $0.3 \%$ CAPTAN fungicide and were then placed in a seed storage plant growth chamber (Aralab ${ }^{\circledast}$ ) at $25{ }^{\circ} \mathrm{C}$ under a 16-h light/8-h dark period (Bacchetta et al., 2008). The plantlets were transplanted to the greenhouse, to $3.5 \mathrm{~L}$ pots from November to April. The growth medium was composed of (v/v): $90 \%$ organic material and $10 \%$ ash content. The soil was similar to peat moss with a pH of 6.2 and $267 \mu$ s of conductivity. The nutrients present in the soil were as follows (\%): C (40.9), $\mathrm{N}(1.1), \mathrm{P}(0.2), \mathrm{K}(0.5)$, Ca (0.6) and $\mathrm{Mg}(0.1)$.

\subsection{Water stress treatment}

The plants were irrigated with water in each plot without creating any water stress for approximately one month, until the plants adapted to the soil conditions. After the aforementioned period, mild water deficit was administered for a set of plants, whereas the control continued to be maintained for the other set. The method used to apply water stress was the gravimetric weight method, which was also used by other researchers in the literature (Salekdeh et al., 2002; Sorial et al., 2010; Alandia et al., 2016). To attain the stipulated values, the soil moisture had to be at $100 \%$ FC. For this purpose, 10 pots (of equal volume to those used in the experiment) full of soil were used. These pots were subjected to multiple irrigations until water started to drain out of the pot. After $24 \mathrm{~h}, 10$ soil samples from these pots were selected. These samples were then weighed and dried under $120^{\circ} \mathrm{C}$ for $24 \mathrm{~h}$ and 
then the weight was measured once again. Soil moisture (volume of water in a given volume of soil) of $100 \%$ FC was determined by the following formula:

$\theta=\frac{\text { Moist soil weight }- \text { Dry soil weight }}{\text { Dry soil weight }}$

The same method was then applied, but this time without irrigation until draining. These calculations were used to determine the base soil moisture without irrigation. Using both sets of data, it was possible to determine the $100 \% \mathrm{FC}$ and $60 \%$ FC. To control the irrigation levels, an electrical balance was used on a daily basis, from the beginning of the application of water stress up until the end of the experiment, assuring that the levels of water stipulated were maintained throughout the experiment.

\subsection{AMF inoculum and mycorrhizal colonization}

Inoculum of $G$. intraradices was obtained from the Plant Biology Department of the Faculty of Sciences, Universidade de Lisboa, Portugal. This is a commercial AMF inoculum (Symbiom ${ }^{\circledR}$ ) consisting of soil, propagules (approximately 100000 per gram) and hyphae. When the basil plants were placed in the $3.5 \mathrm{~L}$ pots, $1 \mathrm{~g}$ of this mixture was added to the planting hole.

To observe whether mycorrhizal fungi colonized the roots of basil plants, root samples were taken at random from each treatment and control. These roots were removed after one month of the plants being in contact with the mycorrhizae. The soil was removed by soaking the roots in water and then gently washing them, to ensure that all thinner roots and tips remained intact. The root fragments were digested in a solution of potassium hydroxide $(\mathrm{KOH})$ at $10 \%$ for $1 \mathrm{~h}$ at $60{ }^{\circ} \mathrm{C}$ in a water bath (Precisbat, Grupo Selecta) to empty the cells of their cytoplasmic contents which facilitates their coloring. After the water bath the roots were thoroughly rinsed with distilled water and placed in a solution of lactoglycerol with trypan blue $(0.05 \%)$. Next, the covers with the tainted root fragments were then observed under a light microscope to visualize the arbuscules, vesicles and mycorrhizal hyphae in accordance to the method outlined by Brundrett et al. (1996).

\subsection{Harvest}

The 1st harvest was carried out after one month of water stress treatment, which corresponds to the three treatments and control (equivalent to 24 plants) and at the 2nd harvest, after two months of water stress, the last set of plants (other 24 plants), were harvested. The plants were harvested at 8 a.m. for fresh material. The 1 st harvest was destined for the analysis of the EO chemical profile during vegetative stage whereas the 2nd harvest was carried out for the analysis of the EO chemical profile during the flowering stage. Before distillation, all plants were deep-frozen at $-20{ }^{\circ} \mathrm{C}$ until the plant material was extracted at the Instituto Politécnico de Bragança, Portugal. The extracted essential oil samples were then maintained at $4{ }^{\circ} \mathrm{C}$.

\subsection{Extraction and analysis}

Each distillation took $3 \mathrm{~h}$ using a Clevenger type apparatus (European Pharmacopeia). Leaves, flowers and stems remained unseparated. Essential oil samples were analyzed by gas chromatography (GC) using a PerkinElmer 8700 gas chromatograph, which was equipped with two flame ionization detectors (FIDs), a data handling system (PerkinElmer TurboChromTM Workstation software), and a vaporizing injector port into which two columns of different polarities were installed: a DB-1 fused-silica column (100\% dimethylpolysiloxane, $30 \mathrm{~m} \times 0.25 \mathrm{~mm}$ i.d., film thickness $0.25 \mu \mathrm{m}$; J \& W Scientific Inc.), and a DB-17HT fused-silica column (50 \%-phenylmethylpolysiloxane, $30 \mathrm{~m} \times 0.25 \mathrm{~mm}$ i.d., film thickness $0.15 \mu \mathrm{m}$; J \& W Scientific Inc.).
Oven temperature was programmed at $45-175{ }^{\circ} \mathrm{C}$, at $3{ }^{\circ} \mathrm{C} / \mathrm{min}$, and subsequently at $15{ }^{\circ} \mathrm{C} / \mathrm{min}$ up to $300{ }^{\circ} \mathrm{C}$, and was then maintained as isothermal for $10 \mathrm{~min}$. Injector and detector temperatures were maintained at $280{ }^{\circ} \mathrm{C}$ and $300{ }^{\circ} \mathrm{C}$, respectively, with the carrier gas (hydrogen) being adjusted to a linear velocity of $30 \mathrm{~cm} / \mathrm{s}$. The samples were injected using the split sampling technique, with a ratio of 1:50. The percentage composition of the volatiles was computed, by the normalization method from the GC peak areas, which was calculated as the mean value of two injections, one from each sample. The gas chromatograph-mass spectrometer (GC-MS) unit consisted of a PerkinElmer Clarus 600 apparatus, which was equipped with DB-1 fused-silica column $(30 \mathrm{~m} \times 0.25 \mathrm{~mm}$ i.d., film thickness $0.25 \mu \mathrm{m})$ and was interfaced with a PerkinElmer Turbomass Clarus $600 \mathrm{~T}$ mass spectrometer. The injector and oven temperatures were the same as those described for the GC analyses. The transfer line and ion source temperatures were set at $280{ }^{\circ} \mathrm{C}$ and $220{ }^{\circ} \mathrm{C}$, respectively. The carrier gas of helium was adjusted to a linear velocity of $30 \mathrm{~cm} / \mathrm{s}$ with a split ratio of 1:40, an ionization energy of $70 \mathrm{eV}$, a scan range of $40-300 \mathrm{u}$ and a scan time of $1 \mathrm{~s}$.

The identification of the components was carried out by comparing their retention indices, in relation to $\mathrm{C}_{9}-\mathrm{C}_{17} n$-alkanes and GC-MS spectra from a lab-made library, which was specifically created with reference essential oils, laboratory-synthesized components, laboratory isolated compounds and commercially available standards.

\subsection{Plant traits}

Regarding the plant traits, the following parameters were determined: plant height $(\mathrm{cm})$ (the plants were measured from the soil surface to the top during the experiment and before each harvest) (Cornelissen et al., 2003) and aboveground and belowground biomass (g plant $^{-1}$ ) (fresh weight (FW)) with a Weswox ${ }^{\circledR}$ electric balance. Roots were sieved with a steel mesh (5 mm diameter) and rinsed with water multiple times. Besides, excess moisture on the roots was dried with blotting paper before measuring root fresh weight, in accordance with Böhm (1979). The latter fresh weights of the aerial part and roots were measured on a scale $( \pm 0.01 \mathrm{~g})$ at $21 \pm 2{ }^{\circ} \mathrm{C}$ of temperature. Aboveground biomass was used for the hydrodistillation.

\subsection{Data analysis}

Since transformed data could not meet ANOVA assumptions, a nonparametric analysis of variance (Kruskall-Wallis test) was carried out, followed by a non-parametric post-hoc test of multiple comparisons (Dunn test) with Benjamini-Hochberg correction. The differences between the means of the treatments and control were deemed to be significant at $p<0.05$. Furthermore, a chi squared independent test was carried out (and when significant, a post-hoc test was used with standardized residuals (Pearson residuals)) to evaluate whether a significant association/dependency exists between the treatments and the chemical compounds. Besides the latter, Duncan's multiple-range test was also used for pairwise comparisons between the means of plant traits results. A paired $t$-test was used to compare population means for the analysis of plant height throughout the experiment (for before-andafter observations on the same subjects).

Furthermore, principal component analysis (PCA) was conducted on the chemical variables to observe possible groupings among treatments applied during cultivation since PCA is very useful for visualizing metabolomics datasets as a first exploratory step (Boccard et al., 2010). Furthermore, a heatmap for each harvest was produced to identify in a more visual way the pattern of the different relative percentage of each chemical compound for each treatment. Statistical analyses and graphs were tested and produced with the R software, program 3.6.0. 


\section{Results and discussion}

\subsection{Plant traits and mycorrhizal colonization}

One of the parameters measured was plants height $(\mathrm{cm})$. Soon after applying the water stress procedure, the height was measured weekly until the end of the experiment. These measurements suggest an increase in plant growth in all the mycorrhizal plants ( $M$ and WSxM) when compared with the non-mycorrhizal plants (control and WS) by the end of the experiment (Graph 1). AMF have been reported to cause an increase in shoot biomass and yield, plant nutrition improvement and also increased growth and development in inoculated plants when compared to non-inoculated plants for many different species, including species from genus Ocimum (Smith and Read, 1997; Berruti et al., 2016). The results of the present work with regards to O. basilicum L. cv. Genovese Gigante appear to agree with such reports.

With regards to the second treatment with seemingly the greatest height (WSxM), it is possible to infer that mycorrhizae possibly had a buffering effect against mild water stress. AMF drives the water status in plants to an optimal level, which thus confirm the role of mycorrhizal symbiosis in the defense of plants against abiotic stresses. In the case of basil, Hazzoumi et al. (2017) showed that water supply deficit was offset in stressed mycorrhizal plants which generate growth at the aerial part. Regarding the WS treatment, it is possible to infer that water stress inhibited the growth of the aerial part. This result has been confirmed by other authors, leading to a conclusion that water stress leads to growth reduction, which is reflected in plant height, leaf area, dry weight, and other growth functions (Boutra et al., 2010). Concerning the non-stressed control plants, without inoculum, it is possible to deduce that this sample presented a higher height in comparison with WS, but that it still had a smaller height than both non-stressed and stressed inoculated plants. Other studies in accordance with these results (Aslani et al., 2011; Hazzoumi et al., 2017) report that plants inoculated with AMF had higher growth, yield and $\mathrm{P}$ uptake than non-inoculated plants under drought stress and non-stress conditions.

However, these measurements are non-significant considering the number of replicas used. In fact, the arbuscular mycorrhizal dependency varies between different plant species and cultivars, and consequently, different growth responses are observed (Tawaraya, 2003; Ruiz-Lozano et al., 2005).

In Table 1, one can see that under well-watered conditions, shoot fresh weights (FW) of AMF and non-AMF basil plants were similar. A significant difference in terms of shoot FW $\left(\mathrm{g} \mathrm{plant}^{-1}\right)$ was observed for the control and water stress treatment in the 2nd harvest. The latter finding is consistent with the general assumption that water stress

\section{Table 1}

Shoot and root FW (fresh weight) in AMF or non-AMF basil plants grown under well-watered or water-stressed conditions.

\begin{tabular}{|c|c|c|}
\hline Treatment & Shoot FW ${ }^{\mathrm{a}}\left(\mathrm{g}_{\text {plant }}{ }^{-1}\right)$ & Root FW ${ }^{\mathrm{a}}\left(\mathrm{g}_{\text {plant }}{ }^{-1}\right)$ \\
\hline \multicolumn{3}{|l|}{ 1st Harvest } \\
\hline \multicolumn{3}{|l|}{ AMF plants } \\
\hline Well-watered (M) & $48.3 \pm 10.70^{\mathrm{a}}$ & $17.3 \pm 5.50^{\mathrm{a}}$ \\
\hline Water-stressed (WSxM) & $37.0 \pm 7.56^{\mathrm{a}}$ & $14.2 \pm 6.28^{\mathrm{a}}$ \\
\hline \multicolumn{3}{|l|}{ Non-AMF plants } \\
\hline Well-watered (C) & $46.0 \pm 11.38^{\mathrm{a}}$ & $14.7 \pm 4.29^{\mathrm{a}}$ \\
\hline Water-stressed (WS) & $38.7 \pm 8.55^{\mathrm{a}}$ & $13.5 \pm 6.89^{\mathrm{a}}$ \\
\hline \multicolumn{3}{|l|}{ 2nd Harvest } \\
\hline \multicolumn{3}{|l|}{ AMF plants } \\
\hline Well-watered (M) & $96.3 \pm 12.51^{\mathrm{a}}$ & $21.0 \pm 4.73^{\mathrm{a}}$ \\
\hline Water-stressed (WSxM) & $107.3 \pm 10.95^{\mathrm{a}}$ & $18.8 \pm 2.94^{\mathrm{a}}$ \\
\hline \multicolumn{3}{|l|}{ Non-AMF plants } \\
\hline Well-watered (C) & $92.3 \pm 8.14^{\mathrm{a}}$ & $16.8 \pm 1.10^{\mathrm{a}}$ \\
\hline Water-stressed (WS) & $75.3 \pm 12.86^{\mathrm{b}}$ & $15.7 \pm 1.41^{\mathrm{a}}$ \\
\hline
\end{tabular}

a Means followed by the same letter are not significantly different $(\mathrm{p}<0.05)$ as determined by Duncan's multiple-range test $(n=6)$ (means of replicates \pm S.D.). reduces plant growth through inhibiting various physiological and biochemical processes, such as photosynthesis, respiration, translocation, ion uptake, nutrient metabolism and hormones (Bahreininejad et al., 2013).

Considering the root $\mathrm{FW}$, it can be seen that the latter parameter was similar in both AMF and non-AMF basil plants, whatever the water regime. However, visible changes caused by the AMF effect on roots length were visible with naked eye. Mycorrhizal plants showed an increased root length under both well-watered and water-stressed conditions (Fig. 1), even though the root fresh weight is similar to the control which is consistent with the previous literature (Smith and Read, 1997; Berta et al., 2002; Copetta et al., 2006).

The values obtained (especially in terms of shoot weight), highlight the importance of including multiple harvests and more replicas to assess responses that have the capacity to change over time, especially plant and fungal growth (Augé, 2001) and also, the responses to prolonged water stress, since both positive and negative interactions between biotic and abiotic factors depend of different variables (Atkinson and Urwin, 2012).

Additionally, no mycorrhizal colonization was observed in plants not inoculated with AMF.

\subsection{Essential oils composition}

The chemical composition of $O$. basilicum L. cv. Genovese Gigante essential oils is presented in Table 2. A total of 24 compounds, representing $86.5-95.8 \%$ of the essential oils, were identified. The major compounds ( $>10 \%$ ) of $O$. basilicum L. cv. Genovese Gigante were linalool (17.0-54.7\%), followed by eugenol (7.1-50.8\%), trans- $\alpha$-bergamotene (0.1-15.4\%) and methyleugenol (0.2-13.1\%). The analyzed essential oils mainly consisted of oxygenated monoterpenes (20.2-64.0\%) followed by phenylpropanoids (7.3-59.2\%), sesquiterpene hydrocarbons (0.4-32.6\%), oxygenated sesquiterpenes (2.4-10.8\%) and monoterpene hydrocarbons (0.6-3.8\%).

Our results strongly support those of Telci et al. (2006), which reported that in Turkey the oxygenated monoterpenes were the major compounds of $O$. basilicum L. essential oils. Similarly, in Bangladesh, $O$. basilicum L. essential oils were reported to have linalool as the main compound (Mondello et al., 2002), while other authors reported that, in Northeast India, camphor, limonene and $\beta$-selinene were the major components (Purkayastha and Nath, 2006). Accordingly, with regards to Genovese Gigante cultivar, it has been described that linalool is also present as the main component $(25.95 \pm 4.20 \%)$ followed by eugenol $(21.81 \pm 8.00 \%)$ at the flowering stage (Labra et al., 2004). These contrasts found in the literature regarding the constituents of basil essential oils across different countries may be due to distinctive environmental and hereditary variables, distinctive cultivars and also the wholesome nutritional status of the plants.

Furthermore, another study of various cultivars of basil (including the Genovese Gigante) asserted that, with regards to the main compounds, all the cultivars were characterized by a high relative percentage of linalool (41-76\%) and relatively abundant amounts of 1,8-cineole (1-12\%), $\tau$-cadinol (2-8\%), and trans- $\alpha$-bergamotene (1-3\%) during the flowering stage (Marotti et al., 1996) - which is in accordance with our results. In addition, the relative percentage which the samples presented (except for the WS samples) regarding eugenol (7.1-21.3\%) agrees with the relative percentage obtained for this compound in EO samples of $O$. basilicum L. grown in Portugal (9.7-17.6\%) (Roque, 1991). The chemical analysis enabled us to confirm that this cultivar is the Genovese Gigante. Regarding the plant traits, this plant grew to an average of $90 \mathrm{~cm}$ during the late flowering stage which characterizes this cultivar, whereas the Genovese cultivar only grows to $40-45 \mathrm{~cm}$ (Flamini et al., 2006). Furthermore, methyleugenol was not found in fully-grown plants, independent of the treatment, thus revealing a low relative percentage, which also characterizes this cultivar (Miele et al., 2001a,b). The aforementioned result 

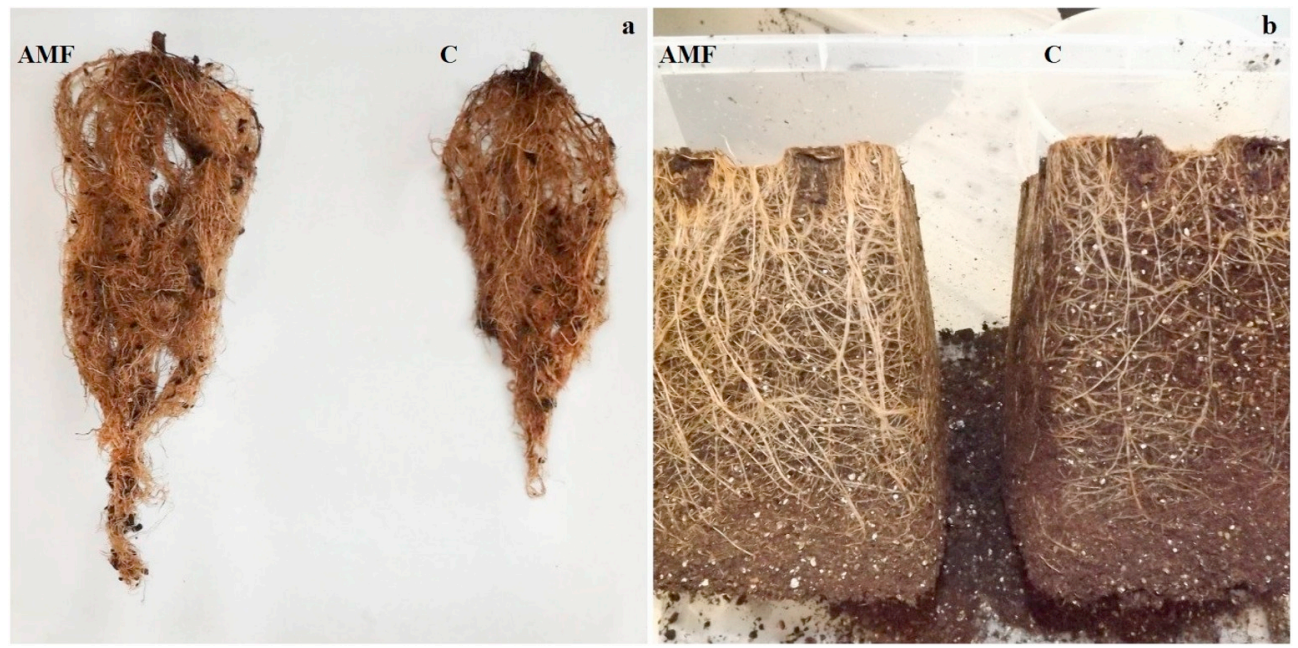

Fig. 1. a) Root branching of basil plants with mycorrhizae treatment (AMF) and control (C) after 133 days, respectively. b) Roots of basil plants with mycorrhizae treatment (AMF) and control (C) after 133 days, respectively.

further confirmed the plant variety used in this experiment.

Having examined these results, and in relation to the common use of this variety as a fresh plant (mainly for consumption purposes), the suggested practice is to harvest this plant during the flowering stage (2nd harvest) when the methyleugenol relative percentage is residual
(Miele et al., 2001a,b; Makri and Kintzios, 2008) in all treatments and the control. When considering other uses, such as the application of the essential oil of this genus for cosmetic or pharmaceutical purposes, the quality traded in Europe, Western Asia, and North America contains larger amounts of 1,8-cineole and linalool, and smaller amounts of

Table 2

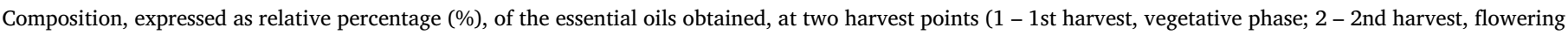

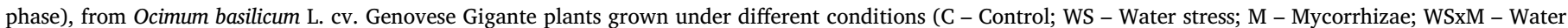
stress + Mycorrhizae).

\begin{tabular}{|c|c|c|c|c|c|c|c|c|c|}
\hline \multirow[t]{2}{*}{ Compounds } & \multirow[t]{2}{*}{$\mathrm{RI}^{\mathrm{a}}$} & \multicolumn{2}{|l|}{$\mathrm{C}$} & \multicolumn{2}{|l|}{ WS } & \multicolumn{2}{|l|}{ M } & \multicolumn{2}{|l|}{ WSxM } \\
\hline & & 1 & 2 & 1 & 2 & 1 & 2 & 1 & 2 \\
\hline (1) Sabinene & 958 & $\mathrm{t}$ & $0.2 \pm 0.04$ & $\mathrm{t}$ & $0.2 \pm 0.07$ & $0.1 \pm 0.03$ & $0.7 \pm 0.01$ & $0.2 \pm 0.01$ & $0.3 \pm 0.01$ \\
\hline (2) $\beta$-Pinene & 963 & $0.2 \pm 0.01$ & $0.8 \pm 0.11$ & $0.7 \pm 0.06$ & $0.6 \pm 0.19$ & $0.6 \pm 0.07$ & $0.2 \pm 0.00$ & $0.7 \pm 0.04$ & $0.6 \pm 0.01$ \\
\hline (3) $\beta$-Myrcene & 975 & $0.1 \pm 0.03$ & $0.6 \pm 0.08$ & $\mathrm{t}$ & $0.6 \pm 0.18$ & $0.5 \pm 0.05$ & $0.7 \pm 0.01$ & $0.7 \pm 0.04$ & $0.7 \pm 0.01$ \\
\hline (4) 1.8-Cineole & 1005 & $0.4 \pm 0.03$ & $6.2 \pm 0.05$ & $4.0 \pm 0.48$ & $5.5 \pm 1.41$ & $0.7 \pm 0.06$ & $6.1 \pm 0.06$ & $2.5 \pm 0.19$ & $5.6 \pm 0.13$ \\
\hline (5) trans- $\beta$-Ocimene & 1027 & $0.2 \pm 0.01$ & $1.5 \pm 0.16$ & $0.6 \pm 0.06$ & $1.3 \pm 0.32$ & $1.1 \pm 0.11$ & $0.5 \pm 0.00$ & $1.9 \pm 0.14$ & $1.2 \pm 0.04$ \\
\hline (6) Terpinolene & 1064 & $0.1 \pm 0.00$ & $0.3 \pm 0.03$ & $0.1 \pm 0.01$ & $0.5 \pm 0.09$ & $0.3 \pm 0.01$ & $0.4 \pm 0.01$ & $0.3 \pm 0.02$ & $0.2 \pm 0.05$ \\
\hline (7) Linalool & 1074 & $17.0 \pm 0.76$ & $46.0 \pm 1.23$ & $25.1 \pm 3.65$ & $52.8 \pm 4.31$ & $27.3 \pm 0.01$ & $54.7 \pm 0.52$ & $21.8 \pm 2.12$ & $48.9 \pm 0.28$ \\
\hline (8) Camphor & 1102 & $0.3 \pm 0.01$ & $0.6 \pm 0.01$ & $0.3 \pm 0.07$ & $0.5 \pm 0.03$ & $0.5 \pm 0.01$ & $0.5 \pm 0.01$ & $0.4 \pm 0.03$ & $0.9 \pm 0.01$ \\
\hline (9) Borneol & 1134 & $0.3 \pm 0.01$ & $0.4 \pm 0.06$ & $0.7 \pm 0.07$ & $0.6 \pm 0.01$ & $0.3 \pm 0.01$ & $0.5 \pm 0.01$ & $0.5 \pm 0.03$ & $0.5 \pm 0.01$ \\
\hline (10) $\alpha$-Terpineol & 1159 & $0.4 \pm 0.01$ & $0.7 \pm 0.02$ & $0.5 \pm 0.16$ & $0.7 \pm 0.01$ & $0.5 \pm 0.01$ & $0.6 \pm 0.01$ & $0.5 \pm 0.04$ & $0.7 \pm 0.01$ \\
\hline (11) Octanyl acetate & 1189 & $0.1 \pm 0.00$ & $0.2 \pm 0.00$ & $\mathrm{t}$ & $0.2 \pm 0.00$ & $0.2 \pm 0.01$ & $0.1 \pm 0.00$ & $0.2 \pm 0.03$ & $0.2 \pm 0.01$ \\
\hline (12) Bornyl acetate & 1265 & $1.8 \pm 0.01$ & $1.6 \pm 0.07$ & $\mathrm{t}$ & $2.6 \pm 0.16$ & $2.6 \pm 0.10$ & $1.6 \pm 0.01$ & $3.2 \pm 0.25$ & $2.0 \pm 0.01$ \\
\hline (13) Eugenol & 1327 & $16.2 \pm 0.14$ & $16.2 \pm 1.05$ & $50.8 \pm 2.02$ & $10.9 \pm 1.84$ & $14.5 \pm 0.13$ & $7.1 \pm 0.06$ & $21.3 \pm 0.36$ & $14.7 \pm 0.02$ \\
\hline (14) Methyleugenol & 1377 & $6.0 \pm 0.17$ & $0.2 \pm 0.06$ & $8.4 \pm 0.66$ & $0.5 \pm 0.11$ & $9.3 \pm 0.10$ & $0.2 \pm 0.01$ & $13.1 \pm 0.44$ & $0.2 \pm 0.11$ \\
\hline (15) $\beta$-Elemene & 1388 & $1.9 \pm 0.06$ & $1.8 \pm 0.12$ & $\mathrm{t}$ & $1.2 \pm 0.23$ & $1.3 \pm 0.12$ & $1.0 \pm 0.04$ & $1.2 \pm 0.03$ & $1.2 \pm 0.02$ \\
\hline (16) trans- $\alpha$-Bergamotene & 1434 & $15.4 \pm 0.47$ & $3.6 \pm 0.25$ & $0.1 \pm 0.01$ & $5.1 \pm 0.75$ & $9.9 \pm 0.22$ & $2.6 \pm 0.01$ & $8.3 \pm 0.10$ & $4.7 \pm 0.06$ \\
\hline (17) $\alpha$-Humulene & 1447 & $1.1 \pm 0.05$ & $3.3 \pm 0.23$ & $\mathrm{t}$ & $0.3 \pm 0.05$ & $0.9 \pm 0.01$ & $0.2 \pm 0.00$ & $0.6 \pm 0.01$ & $0.3 \pm 0.05$ \\
\hline (18) trans- $\beta$-Farnesene & 1455 & $3.6 \pm 0.10$ & $0.2 \pm 0.14$ & $\mathrm{t}$ & $0.3 \pm 0.06$ & $3.4 \pm 0.04$ & $2.6 \pm 0.01$ & $2.9 \pm 0.10$ & $0.3 \pm 0.04$ \\
\hline (19) Germacrene D & 1474 & $5.8 \pm 0.12$ & $2.3 \pm 0.17$ & $\mathrm{t}$ & $2.6 \pm 0.47$ & $3.5 \pm 0.04$ & $2.3 \pm 0.06$ & $2.6 \pm 0.10$ & $2.5 \pm 0.06$ \\
\hline (20) $\gamma$-Cadinene & 1500 & $4.5 \pm 0.06$ & $1.2 \pm 0.08$ & $0.3 \pm 0.28$ & $1.2 \pm 0.23$ & $2.8 \pm 0.03$ & $2.0 \pm 0.24$ & $1.7 \pm 0.14$ & $1.4 \pm 0.04$ \\
\hline (21) $\beta$-Sesquiphellandrene & 1508 & $0.3 \pm 0.04$ & $0.3 \pm 0.01$ & $\mathrm{t}$ & $0.3 \pm 0.06$ & $0.6 \pm 0.04$ & $0.9 \pm 0.01$ & $0.6 \pm 0.07$ & $0.2 \pm 0.02$ \\
\hline (22) $\tau$-Cadinol & 1616 & $9.2 \pm 0.11$ & $3.6 \pm 0.24$ & $1.5 \pm 0.21$ & $3.6 \pm 1.17$ & $1.3 \pm 0.15$ & $1.9 \pm 0.00$ & $6.0 \pm 1.06$ & $3.9 \pm 0.11$ \\
\hline (23) Cubenol & 1624 & $0.9 \pm 0.52$ & $0.7 \pm 0.02$ & $2.0 \pm 0.45$ & $0.9 \pm 0.02$ & $0.7 \pm 0.04$ & $0.3 \pm 0.24$ & $1.5 \pm 0.23$ & $0.6 \pm 0.08$ \\
\hline $\begin{array}{l}\text { (24) } \alpha \text {-Cadinol } \\
\% \text { of identification }\end{array}$ & 1626 & $\begin{array}{l}0.7 \pm 0.03 \\
\mathbf{8 6 . 5}\end{array}$ & $\begin{array}{l}0.4 \pm 0.06 \\
92.9\end{array}$ & $\begin{array}{l}0.7 \pm 0.26 \\
95.8\end{array}$ & $\begin{array}{l}0.5 \pm 0.19 \\
93.5\end{array}$ & $\begin{array}{l}1.0 \pm 0.16 \\
83.9\end{array}$ & $\begin{array}{l}0.2 \pm 0.04 \\
87.9\end{array}$ & $\begin{array}{l}0.9 \pm 0.09 \\
93.6\end{array}$ & $\begin{array}{l}0.5 \pm 0.01 \\
92.3\end{array}$ \\
\hline \multicolumn{10}{|l|}{ Grouped compounds } \\
\hline Monoterpene hydrocarbons & & $0.6 \pm 0.06$ & $3.4 \pm 0.43$ & $1.4 \pm 0.14$ & $3.2 \pm 0.86$ & $2.6 \pm 0.28$ & $2.5 \pm 0.02$ & $3.8 \pm 0.25$ & $3.0 \pm 0.12$ \\
\hline Oxygenated monoterpenes & & $20.2 \pm 0.83$ & $55.5 \pm 1.44$ & $30.6 \pm 4.43$ & $62.7 \pm 5.93$ & $31.9 \pm 0.18$ & $64.0 \pm 0.60$ & $28.9 \pm 2.66$ & $58.6 \pm 0.45$ \\
\hline Sesquiterpene hydrocarbons & & $32.6 \pm 0.91$ & $12.7 \pm 1.01$ & $0.4 \pm 0.28$ & $11.0 \pm 1.84$ & $22.4 \pm 0.50$ & $11.6 \pm 0.38$ & $17.9 \pm 0.55$ & $10.6 \pm 0.29$ \\
\hline Oxygenated sesquiterpenes & & $10.8 \pm 0.66$ & $4.7 \pm 0.33$ & $4.2 \pm 0.92$ & $5.0 \pm 1.36$ & $3.0 \pm 0.35$ & $2.4 \pm 0.28$ & $8.4 \pm 1.38$ & $5.0 \pm 0.21$ \\
\hline Phenylpropanoids & & $22.2 \pm 0.31$ & $16.4 \pm 1.12$ & $59.2 \pm 2.68$ & $11.4 \pm 1.94$ & $23.8 \pm 0.18$ & $7.3 \pm 0.08$ & $34.4 \pm 0.81$ & $14.9 \pm 0.13$ \\
\hline Others & & $0.1 \pm 0.00$ & $0.2 \pm 0.00$ & $\mathrm{t}$ & $0.2 \pm 0.00$ & $0.2 \pm 0.01$ & $0.1 \pm 0.00$ & $0.2 \pm 0.03$ & $0.2 \pm 0.01$ \\
\hline
\end{tabular}

Values (relative percentage) are given as mean \pm S.D.

$\mathrm{t}$ - trace amount $(<0.05 \%)$.

${ }^{\text {a }}$ Retention index calculated relative to C9-C17 n-alkanes on the DB-1 column. 
methyleugenol and eugenol (Simon et al., 1999), and, as such, it is suggested that the optimal stage to harvest $O$. basilicum L. cv. Genovese Gigante for these purposes is during the flowering stage (2nd harvest) for all the treatments and the control. Indeed, the results of a chisquared independent test applied to the data of Table 2 indicate that significant differences are present with regard to the vegetative stage ( $p=0.04908$ ) (1st harvest) in contrast with the flowering stage. These significant differences regarding the WS in comparison with that of the control and the other treatments are explained by the compounds trans$\alpha$-bergamotene and eugenol. For this reason, the quality of the WS samples is inadequate considering the quality traded in Europe, Western Asia, and North America above mentioned.

\subsection{Ontogeny-related variability}

The compounds that notably varied to some extend with ontogeny were linalool (the largest contribution during the flowering stage, 2nd harvest: 45.9\%), 1,8-cineole (the largest amount during the flowering stage: $6.2 \%$ ) and trans- $\alpha$-bergamotene (the largest amount during the vegetative stage, 1st harvest: $15.3 \%$ ) while eugenol did not vary from the 1 st to the 2nd harvest in the control samples. These relative percentages are in accordance with Lemberkovics et al. (1993), which asserted that at early stages of flowering, linalool and sesquiterpenes constituted $40-60 \%$ and sesquiterpenes $5-20 \%$ in $O$. basilicum L. (sweet basil).

In Graph 2A, which shows the PCA biplot of EO samples from the control and the other three treatments, it is possible to observe that the first principal component (dim1) explains $83.3 \%$ of the sample's variation. Therefore, independent of the treatment, the main clusters formed are related to the class of phenylpropanoids and oxygenated monoterpenes.

Regarding EO samples from the control, the contents of oxygenated components (the sum of oxygenated monoterpenes and oxygenated sesquiterpenes) present in the essential oils were higher during the flowering stage (60.2\%), 2nd harvest, and lower during the vegetative stage (23.4\%), 1st harvest. Furthermore, during the flowering stage the monoterpene hydrocarbons were $3.5 \%$, whereas during the vegetative stage they were $0.5 \%$ in the control samples. An opposite trend was observed for sesquiterpene hydrocarbons. The relative level of this class of compounds reached a maximum of $32.6 \%$ during the vegetative stage and the minimum during the flowering stage (12.6\%).

A possible explanation for the relative percentage of OM observed in the 2nd harvest could be related to the lower level of enzyme activity of PAL (negatively correlated to height), which tends to restrict the phenylpropene pathway and increase the flux in the terpene pathway (Iijima et al., 2004) and/or the relative increase of OM (which is mainly due to the relative percentage variation of linalool), which could be due to the function of linalool as a behaviorally-attractive compound for many insects (Raguso and Pichersky, 1999), which is a key compound when plants reach the flowering stage. Additionally, and likewise, other authors also noticed with 5 Ocimum species that OM relative percentage increased and phenylpropanoids decreased from vegetative stage to full bloom stage (Padalia et al., 2013).

According to the PCA biplot which considers the treatments (Graph 2B), the variants all largely overlapped under the treatments and control conditions. However, the WS treatment was slightly distinct, with WS following the 1st harvest (vegetative stage) loading vector direction. Indeed, WS samples had a relative percentage of phenylpropanoids substantially increased under water stress conditions during the 1 st harvest. However, it is inferred by the biplot that an ontogeny-related pattern remained intact even in water stressed plants. The difference between these treatments can only be attributable to constitutive and de novo biosynthesis.

It is by now generally accepted that the constitutive emissions are described based on genetically determined emission potentials. Various environmental conditions are responsible for the expression of this species-specific potential, from which temperature and radiation are the most important ones, both for short- and longer-term impacts (Grote et al., 2019). In this experiment, the temperature was controlled whereas the radiation (i.e. seasonal variations) was not. Nevertheless, the phenylpropanoids eugenol and methyleugenol of genus Ocimum show no consistent seasonal pattern according to other authors (Miele et al., 2001a,b; Rakic and Johnson, 2002). As such, these basic findings seem consistent with research showing that de novo emissions of stressinduced compounds may excel constitutive emissions by more than an order of magnitude and often have a considerable different compound composition (Grote et al., 2019). In summary, the essential oil profile was altered under water stress conditions, although these changes follow a species-specific emission pattern. In fact, the metabolic processes activated in defense responses may be tightly separated or overlapping, according to the stress factor and the plant cultivar, as a result of negative (trade off) or positive (cross resistance) cross talk, respectively, i.e., the communication between molecular signals and transduction pathways involved in different plant defense responses (Iriti and Faoro, 2009; Kravitz et al., 2016). These basic findings are consistent with research showing that PAL (first enzyme in the phenylpropanoid pathway) is an extremely sensitive indicator of stress conditions, and it is commonly considered as a biochemical marker indicating the activation of plant defenses (Iriti and Faoro, 2009). For these reasons, the data is well-suited for further analysis.

\subsection{Quality variation in response to the biotic and abiotic factor}

The relative percentage of each chemical compound from each treatment and control are represented by a heatmap in order to better visualize the different patterns (Fig. 2).

It is possible to observe, that WS treatment largely altered the relative percentage proportion of the essential oil compounds (with a high relative percentage of mainly phenylpropanoids, while maintaining a very low relative percentage values for other compounds such as bornyl acetate, germacrene D, and others, with a green color) in comparison with the control. It has been asserted that the carbon flow can be readily redirected between the phenylpropanoid and terpenoid pathways (Xie et al., 2008). Indeed, some basil lines with reduced biosynthesis of phenylpropanoids and increased biosynthesis of terpenoids appear to have resulted from a reduced flux in the shikimate/ phenylpropanoid pathway and a diversion of upstream metabolite intermediates into the MEP and subsequent terpenoid pathways (Xie et al., 2008). It has been reported that water stress has negative effects on carbon gain/flow, which is caused by closure of stomata, which thus increases stomatal resistance (Kluge, 1976). Accordingly, this reduction in $\mathrm{CO}_{2}$ assimilation capacity could have redirected resources to the shikimate/phenylpropanoid pathway (in detriment of the terpenoid pathways), since phenylpropanoid synthesis has been proved to be highly related to water stress response.

Furthermore, plants need a well-balanced trade-off which permits growth without excluding defense responses (Caretto et al., 2015). This trade-off depends on photosynthesis-synthesized carbon skeletons, which are dynamically used for growth or defense (Caretto et al., 2015). A way to optimize the use of carbon resources is through shared pathways for both primary and secondary metabolism (growth and defense), as, for example, the formation of lignin and phenylpropanoids. Indeed, the allocation of carbon skeletons for both metabolisms can take place at the same time in plants (McKey, 1979). This strict relationship is described by reports which affirm that phenolic levels increase during stress since growth is inhibited more than photosynthesis (Caretto et al., 2015). This possibly explain the differences seen in the samples of the essential oil from the WS treatment in terms of phenylpropanoids and lower terpenoid proportion. The existence of rather different proportions of classes of compounds in the WS samples in the heatmap is further confirmed by Table 3. The WS treatment samples had a significantly different chemical profile (or distribution) 


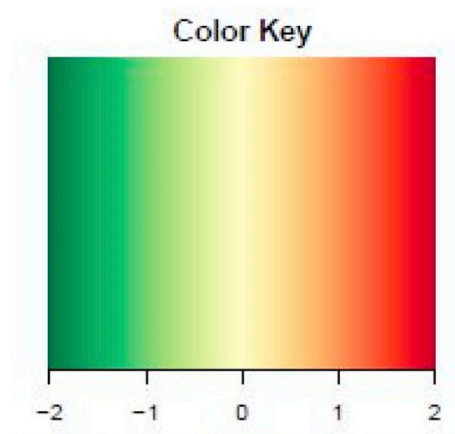

\section{1st Harvest EO samples}
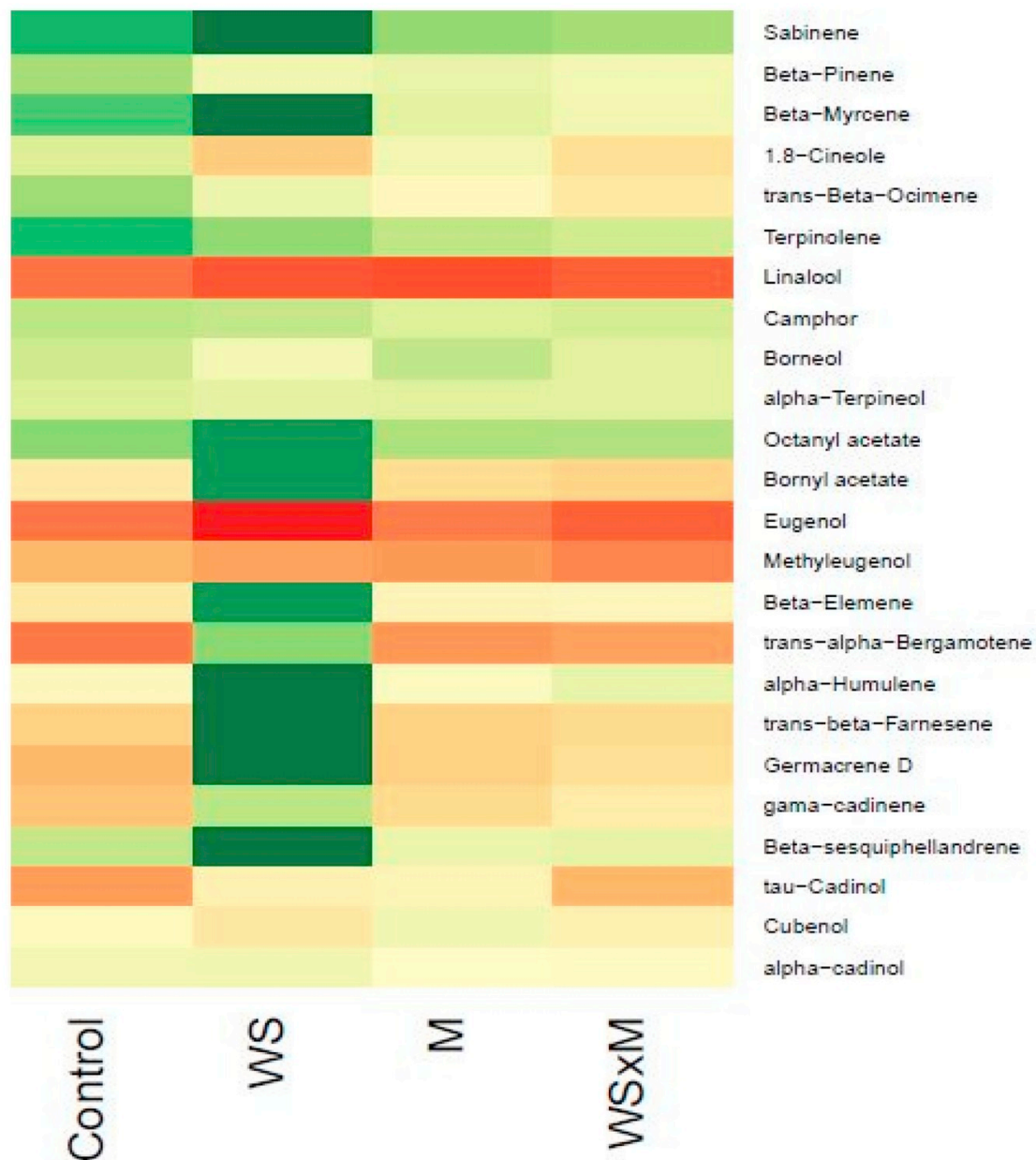

Fig. 2. Heatmap pattern of the essential oil constituents from the 1st harvest. C - Control; WS - Water Stress treatment; M - Mycorrhizae treatment; WSxM - Water stress and Mycorrhizae treatment.

in comparison with the control, which is in accordance with other studies (Simon et al., 1992; Ekren et al., 2012; Selmar and Kleinwachter, 2013). Furthermore, the post-hoc analysis of the chisquared test revealed that this difference is solely due to the trans- $\alpha$ bergamotene and eugenol compounds, as mentioned previously. In addition, no significant differences were found regarding the control and $\mathrm{M}$ treatment, neither the control condition and WSxM treatment with respect to essential oil profile and the distribution of the chemical compounds.

In summary, the enhancement of PAL activity due to water stress (Xie et al., 2008) and the changed ratio of certain secondary metabolites of medicinal plants due to an early contact defense response to AMF colonization and/or due to higher nutrient availability to synthetize terpenoids which are resource-demanding (Chaudhary et al.,
2008; Zeng et al., 2013; Kapoor et al., 2016) could explain the similarities and differences observed in Table 3.

A principal component analysis (PCA) was carried out to reduce dimensionality and to better understand the aforementioned differences with respect to each chemical compound (Graph 3).

PCA-based chemical composition data of essential oils accounted for $92.2 \%$ of the sample's variance and clearly discriminated between the three treatments and the control. Treatments of inoculated plants (both water stressed or non-water stressed) are plotted near to each other (upper left quadrant), but are distant from both WS treatment (bottom right quadrant) and the Control (bottom left quadrant).

As showed in Graph 3, the main ordination axis (which accounts for about $55.2 \%$ of the total variation) was (in decreasing order of contribution) significantly positively correlated with eugenol, borneol, 
Table 3

Statistical evaluation, by Kruskal-Wallis test, of the composition of the essential oils from AMF or non-AMF basil plants grown under well-watered or water-stressed conditions from the 1st harvest. The null hypothesis is rejected (Kruskal-Wallis chi-squared $=18.22$, $\mathrm{df}=3$, $p=0.0004)$.

\begin{tabular}{ll}
\hline Treatment & Essential oil profile (\%) $^{\mathrm{a}}$ \\
\hline 1st Harvest & \\
Non-AMF plants & $3.60 \pm 5.41^{\mathrm{b}}$ \\
Well-watered (C) & $3.99 \pm 11.27^{\mathrm{a}}$ \\
Water-stressed (WS) & \\
AMF plants & $3.50 \pm 6.24^{\mathrm{b}}$ \\
Well-watered (M) & $3.90 \pm 6.20^{\mathrm{b}}$ \\
Water-stressed (WSxM) & \\
\hline
\end{tabular}

Groups sharing a letter are not significantly different $(p<0.05)$ as determined by Kruskal Wallis test and Dunn's post-hoc test.

a Mean \pm S.D. cubenol, 1,8-cineole, $\alpha$-terpineol, linalool and $\beta$-pinene. The WSxM and $\mathrm{M}$ treatments and also the control were negatively related to the main axis, which indicates that WS had significant effects on the synthesis of specific compounds of certain classes. Furthermore, WS was significantly positively correlated with eugenol, specifically, in the positive axis of PC1, which showed the greatest positive loading, which thus explains that the variation of this principal component is eugenol (the highest positive score), whereas the negative axis of PC1 had as the highest negative scores trans- $\alpha$-bergamotene, trans- $\beta$-farnesene, $\beta$-elemene and $\tau$-cadinol. In fact, the relative percentage of each of these compounds in the positive axis of PC1 were higher in WS (as 1,8-cineole and eugenol) and the relative percentage of the compounds in the negative axis of PC1 (as trans- $\alpha$-bergamotene and $\tau$-cadinol) were higher in the Control, WSxM and M. Additionally, under water stress conditions, basil plants showed a markedly lower relative percentage of hydrocarbon sesquiterpenes (like trans- $\alpha$-bergamotene) compared to the control plants and inoculated plants.

Dim2 or PC2 accounted for $37 \%$ of the total variation and was

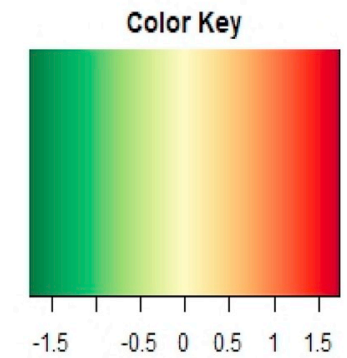

\section{2nd Harvest EO samples}

$\log 10$ (Relative $\%$ of chemical compounds)

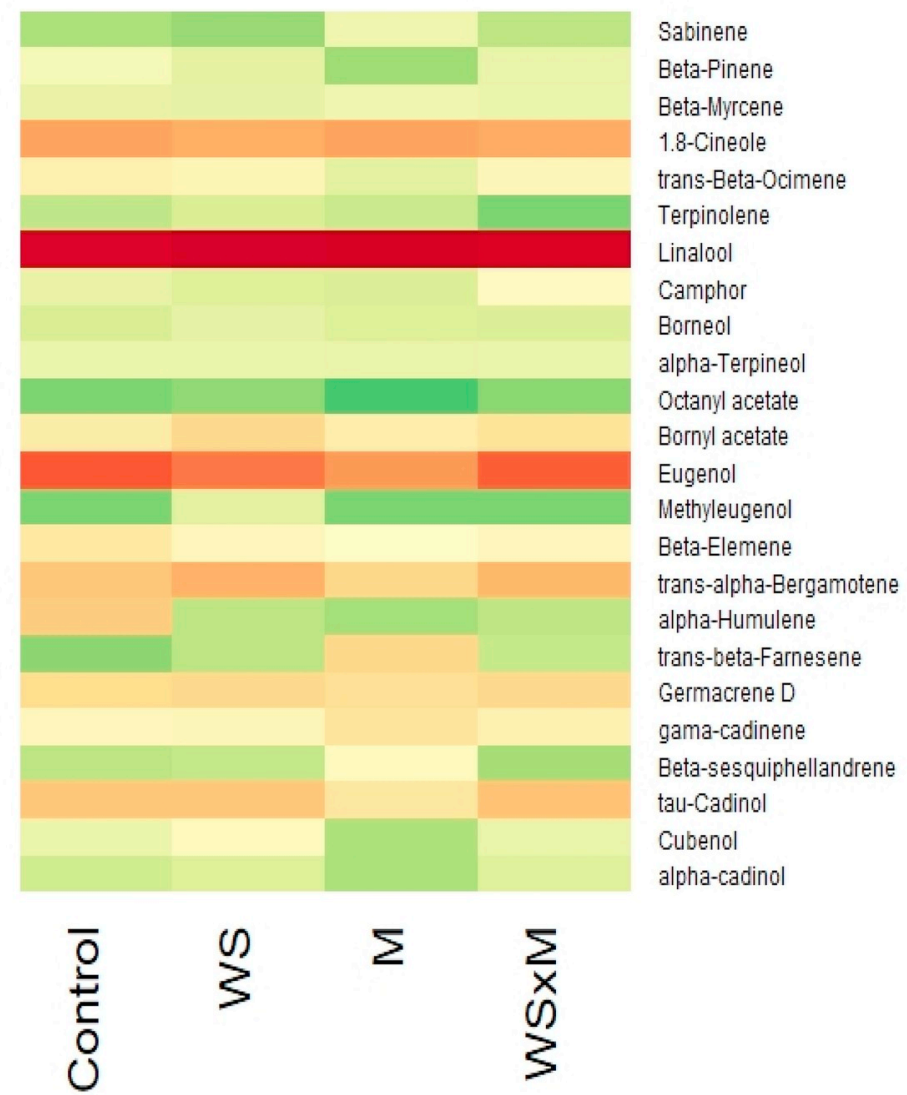

Fig. 3. Heatmap pattern of the essential oil constituents from the 2nd harvest. C - Control; WS - Water Stress treatment; M - Mycorrhizae treatment; WSxM - Water stress and Mycorrhizae treatment. 
mainly influenced by non-oxygenated monoterpenes (as trans- $\beta$ Ocimene) and by methyleugenol. Nevertheless, methyleugenol percentage does not vary significantly between treatments, but rather increases in samples of inoculated plants (WSxM and M).

The linalool compound, which is present in the positive axis of PC1 and PC2, had a low positive loading in both components in comparison with the other chemical compounds. In fact, the range by which this compound varied is rather small between treatments and the control (17-27\%), this could be more associated with ontogeny, since different articles suggest that plants from the genus Ocimum, during the preflowering stage, present $22.24 \pm 1.66 \%$ of linalool (Toncer et al., 2017), which is in accordance with the results obtained in our research. However, in contrast to M, WSxM and control, the WS treatment did not present linalool as the main compound.

Indeed, Miele et al. (2001a,b) asserted that in locations with a mild climate, eugenol was prevalent in the essential oil samples rather than linalool in Genovese Gigante plants (Miele et al., 2001a,b). These locations are characterized by different environmental factors including the amount of water available. As mentioned above, PAL, which is an enzyme which plays an active role in the biosynthesis of the main fragrance phenylpropanoids (as eugenol) in glandular peltate trichomes of Ocimum basilicum L. (Xie et al., 2008), is reported to increase its activity in plants under water stress conditions, which has also been tested and confirmed by other authors (Luna et al., 2015; Hazzoumi et al., 2017). Besides eugenol, methyleugenol relative percentage was also higher in the EO samples from WS and WSxM in comparison with the control. However, WSxM treatment samples, which are present in the same quadrant as the $M$ samples, approach the quality of the samples from $\mathrm{M}$ treatment and distance themselves from samples of WS treatment.

Considering the trans- $\alpha$-bergamotene relative percentage presented in the control EO samples, the value of $15.4 \%$, is in accordance with that observed by other authors that harvested genus Ocimum plants during the pre-flowering stage, who reported a relative percentage of this compound of $14.9 \%$ (Yayi et al., 2001). However, in the WS treatment samples, the relative percentage of trans- $\alpha$-bergamotene presented a low relative amount, which could be explained by the findings of previous reports that $50 \% \mathrm{FC}$ water stress had a deleterious effect in sesquiterpene hydrocarbons synthesis in other essential oilbearing plants (Caser et al., 2017).

Considering the 2nd harvest and the corresponding heatmap (Fig. 3), one can observe a different pattern from that seen for the 1st harvest.

In the case of the 2 nd harvest, the chemical profiles (variation between 87.9 and $93.5 \%$ ) from the samples of the different treatments are not strikingly divergent (Table 4). This observation could be explained by an absence of de novo biosynthesis - possibly due to acclimation, i.e., an adjustment of the metabolic pathways reestablishing homeostasis (Shulaev et al., 2008). The linalool compound in the samples of the control and the treatments was the main compound observed, varying between 46 and 55\%, which is in accordance with the relative percentage of linalool obtained in samples from this cultivar during the flowering stage (Marotti et al., 1996). Regarding eugenol, Renu et al. (2014) reported that there is a higher level of eugenol-o-methyltransferase (EOMT) transcripts during the juvenile and pre-flowering stage and that, conversely, a remarkable decrease of EOMT transcripts occurs during the post-flowering stages of several chemotypes, which indicates an extensive transcriptional reprogramming associated with decreased accumulation of the metabolites. Similarly, during the flowering stage, when the 2nd harvest was carried out, the essential oil samples presented relatively low amounts of methyleugenol and eugenol, which decreased from the 1st to the 2nd harvest, independent of the treatment applied. Therefore, the seemingly pronounced reduction of the relative percentage of methyleugenol (to $0.15-0.52 \%$ ), by this stage of growth, is consistent with other studies (Miele et al., 2001a,b; Khakdan et al., 2017). Furthermore, the decrease of eugenol could be associated with a rapid turnover of eugenol, which might be used by the plant for lignin biosynthesis (Manitto et al., 1974). The above mentioned could indicate that the values obtained for the last-mentioned three compounds are more related with genetic, ontogenic and morphogenetic factors than with environmental ones, which could entail an ontogeny-related compensatory response to water stress. Indeed, growth regulators serve as an integral component of plant response to both biotic and abiotic stresses (Iriti and Faoro, 2009).

According to the principal component analysis of the 2nd harvest (Graph 4) (which accounts and explains $88 \%$ of the sample's variance) it is possible to observe that the discrimination between the three treatments and the control condition is distinct from that observed in the 1st harvest, where, treatments of inoculated plants and those under water stress, WSxM, and in the Control condition are all plotted near each other (upper left quadrant); $M$ treatment is plotted in the bottom right quadrant and WS is in the bottom left quadrant.

The PC1 or main ordination axis in this harvest accounted for about $62 \%$ of the total variation and was positively correlated (in decreasing order of contribution) to sabinene, trans- $\beta$-farnesene, $\gamma$-cadinene, $\beta$ sesquiphellandrene, $\beta$-myrcene, linalool, 1,8-cineole and terpinolene. Control, WSxM and WS treatment were negatively correlated to the main ordination axis - which indicates that, contrary to what was observed in the 1 st harvest, the largest variation of this harvest is explained by minor chemical compounds. The PC2 accounted for $27 \%$ of the total variation, with the main contributors being $\alpha$-humulene, $\beta$ elemene, 1,8-cineole, eugenol, $\beta$-pinene, camphor, trans- $\beta$-ocimene and $\tau$-cadinol in decreasing order of contribution respectively.

Regarding the main compound of this harvest in the control samples and the treatments, linalool, it is observed that this compound had the lowest positive value in terms of contribution to the PC1, i.e., to the major explained variation. Furthermore, a relative increment of this compound from the 1st to the 2nd harvest is observed for all treatments and for the control. This in accordance with other studies, which concluded that maximum linalool content is obtained from the inflorescence at the commencement of flowering in basil (NurzyńskaWierdak et al., 2012). Similarly, another study with O. basilicum L. reported that the range of linalool in the control and with three AMF species varied from 63.9 to $66.7 \%$ with the highest relative percentage being obtained with inoculated plants (Rasouli-Sadaghiani et al., 2010). On the contrary, eugenol decreased in all treatments in comparison with the 1st harvest. According to some authors, the lower relative percentage in WS and M treatment of this compound could be related to the activity of PAL in other species, which significantly increases in the leaves under the early stages of water stress but decreases gradually as the period of stress is extended (Lee et al., 2007; Wang et al., 2016), whereas, with regards to the M treatment, according to Volpin et al. (1994), this could be due to the activity declining rapidly, after reaching maximum levels of PAL activity. Indeed, Volpin et al. (1994) conclude that it is reasonable to suggest that a nonspecific defense response is induced following the fungal colonization, which is subsequently specifically depressed. With regards to 1,8-cineole, there was an increase from the 1 st to the 2 nd harvest in all the treatments and the control where values ranged from 5.5 to $6.2 \%$ - which is in accordance with the assumption that the concentration of the compounds such as 1,8-cineole, camphor, cis-thujone, limonene and trans-thujone are the lowest during early stages of development in other essential oil-bearing plants (Lee and Ding, 2016).

As mentioned above, the apparent lack of influence of the application of water stress and/or AMF on the proportion of the compounds in comparison with the control during the 2 nd harvest could be due to an acclimation process (possibly related to ontogeny) (Winkel et al., 2001; Iridi et al., 2009) or the tolerance of the plants (Yordanov et al., 2000; Tarchoune et al., 2010) to the treatments, since the duration of the latter was extended. To be sure of these processes more data would be required. 


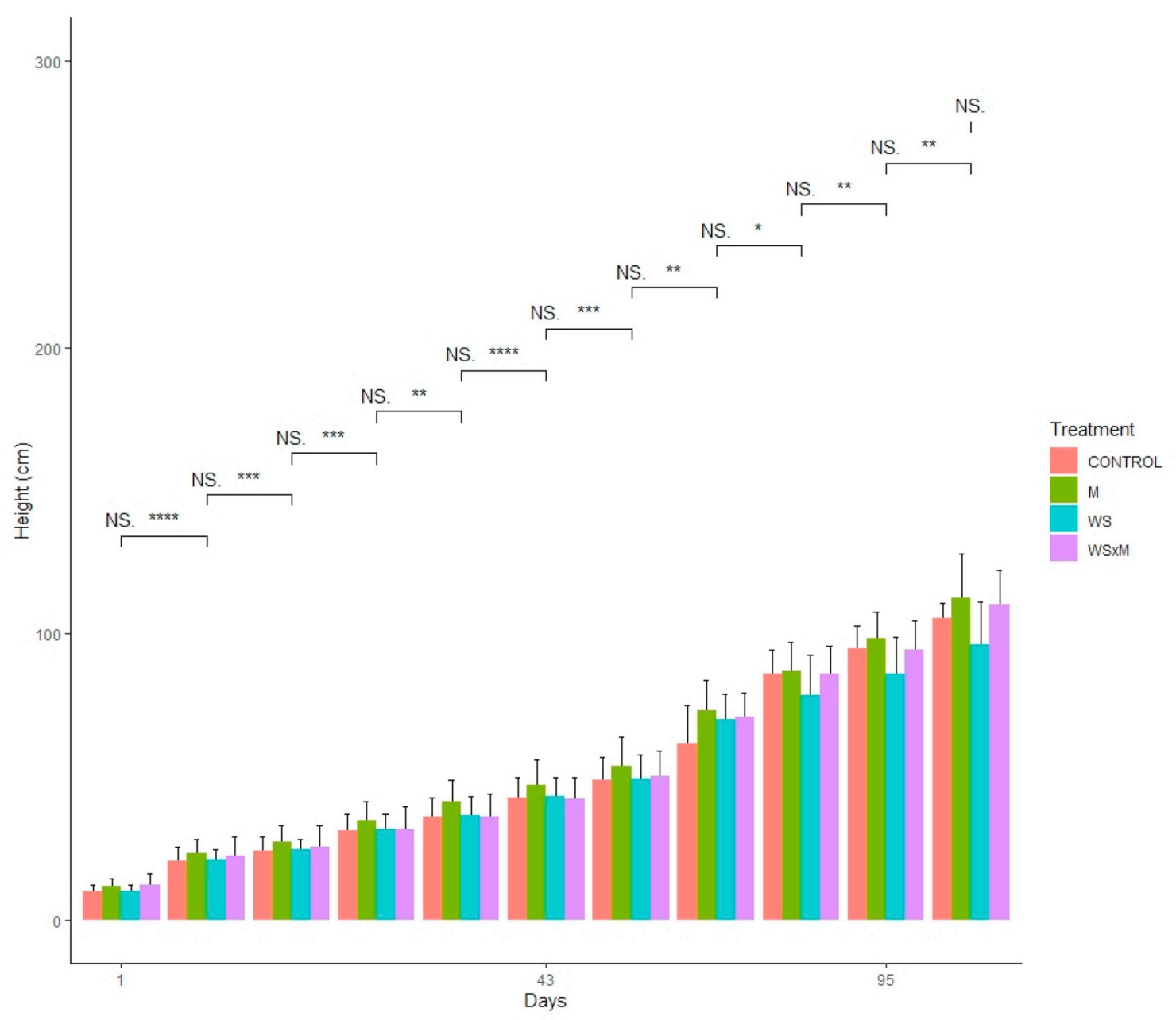

Graph 1. Plant growth of Ocimum basilicum L. cv. Genovese Gigante plants measured as shoot length $(\mathrm{cm})$ under greenhouse conditions up until the 2nd harvest. The data of the graph is the mean of 12 replicates up until day 32 and from this point onwards, the mean is of 6 replicas. C: Control; WS: Water Stress; M: Mycorrhizae; WSxM: Water Stress x Mycorrhizae. The statistical test between days and in-between groups for each day was carried out with a paired $t$-test.
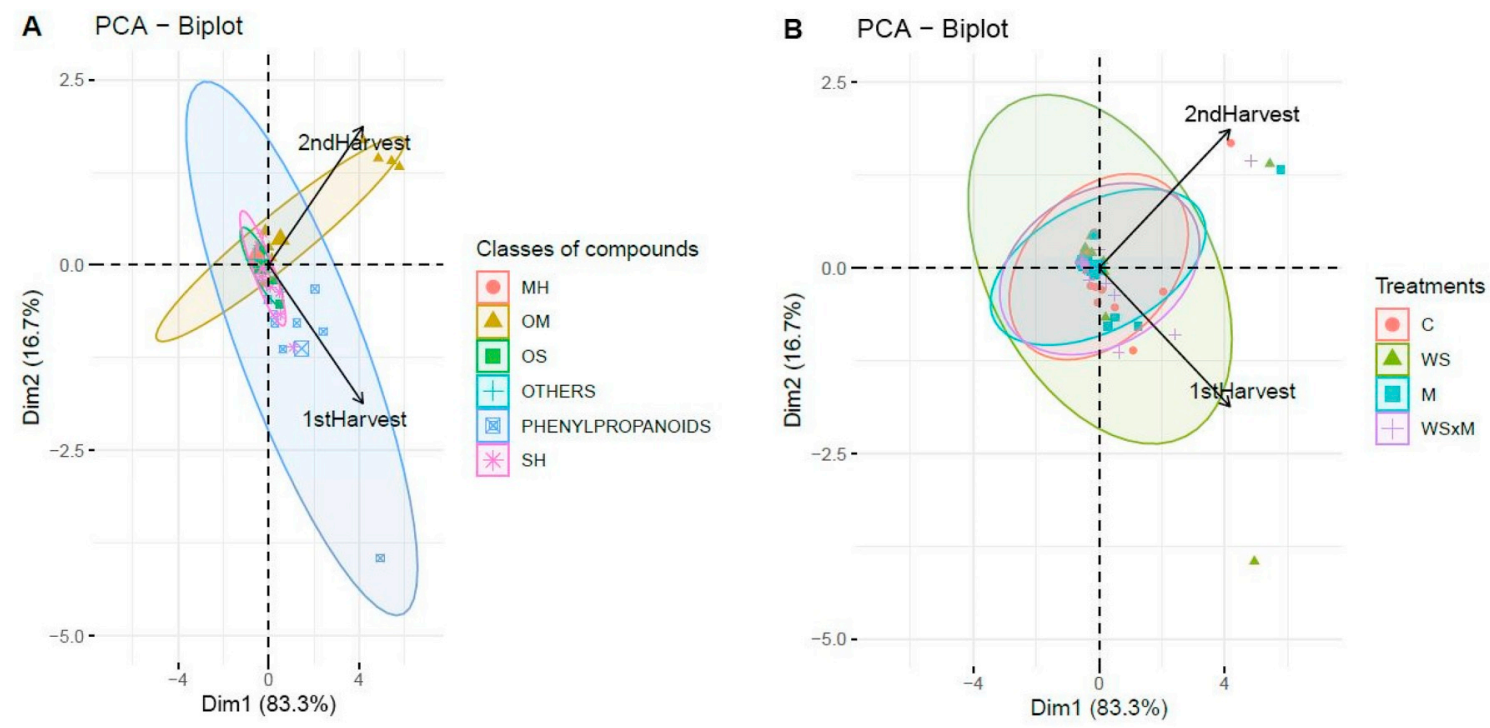

Graph 2. Principal components analysis biplot - scores and loadings of the chemical profile of essential oils from the 1st harvest (vegetative stage) and the 2nd harvest (flowering stage) of the control and WS, M and WS x M treatments. A. Clustering based on classes of compounds ('MH' - Monoterpene hydrocarbons; 'OM' Oxygenated monoterpenes; 'OS' - Oxygenated sesquiterpenes; 'Others'; 'Phenylpropanoids' and 'SH' - Sesquiterpene hydrocarbons). B. Clustering based on treatments ('C' - Control; 'WS' - Water stress treatment; 'M' - Mycorrhizae treatment; 'WSxM' - Water stress and Mycorrhizae treatment). 


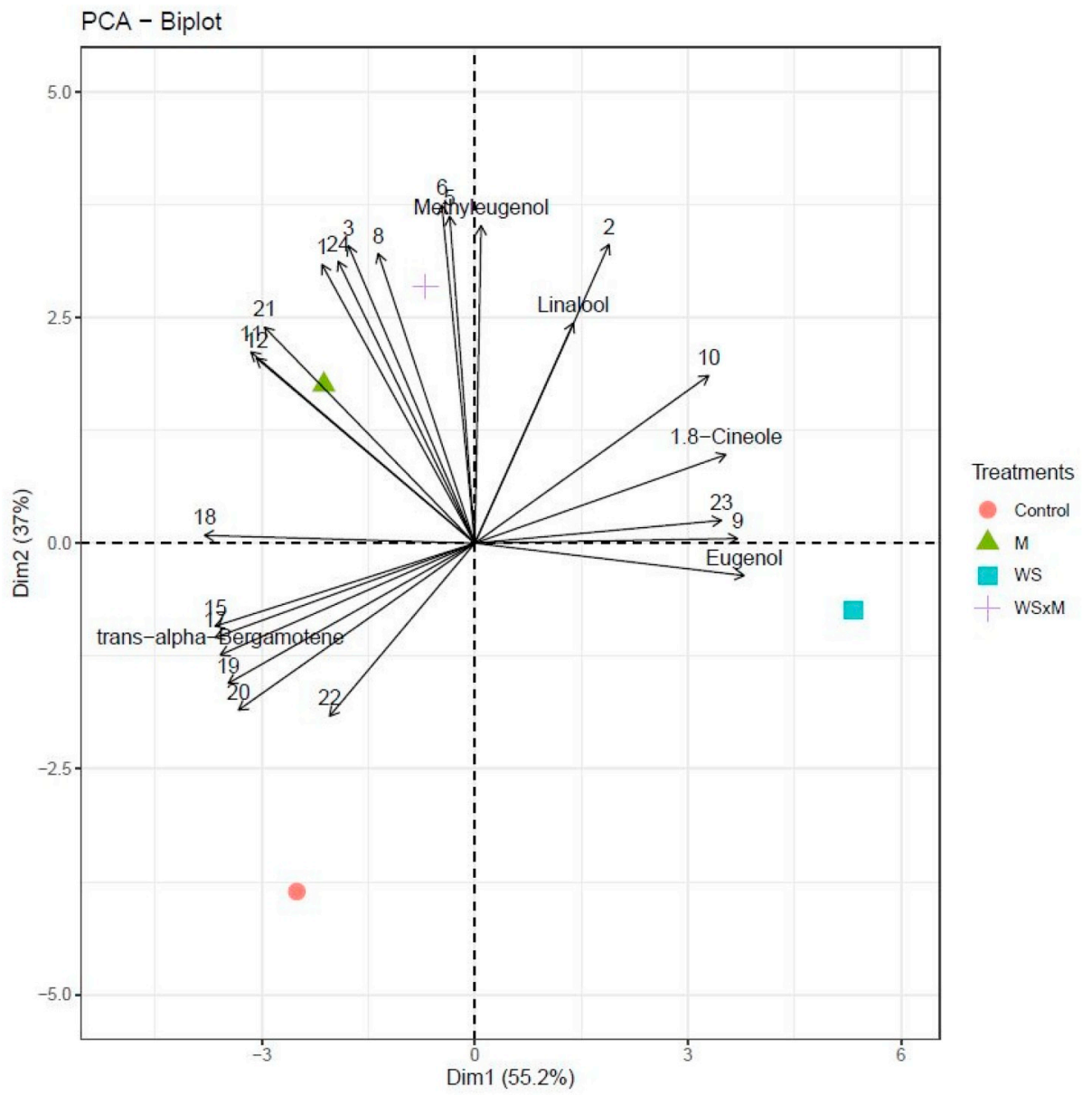

Graph 3. PCA biplot of chemical variation of $O$. basilicum $L$. cv. Genovese gigante under different conditions from the 1st harvest EO samples. Sample numbers are ordered according to the ascending values of the retention index (RI); these numbers are assigned in the first column of Table 2. Different shapes represent mean PC scores for treatments. Arrows are scaled vectors of the strongest loadings for individual chemical compounds on PC1 and PC2.
Table 4

Statistical evaluation, by Kruskal-Wallis test, of the composition of the essential oils from AMF or non-AMF basil plants grown under well-watered or water-stressed conditions from the 2nd harvest. The null hypothesis is not rejected (Kruskal-Wallis chi-square $=0.420 \mathrm{df}=3$, $p=0.9361)$.

\begin{tabular}{ll}
\hline Treatment & Essential oil profile (\%) ${ }^{\mathrm{a}}$ \\
\hline 2nd Harvest & \\
Non-AMF plants & $3.86 \pm 9.57^{\mathrm{a}}$ \\
Well-watered (C) & $3.88 \pm 10.71^{\mathrm{a}}$ \\
Water-stressed (WS) & \\
AMF plants & $3.66 \pm 11.03^{\mathrm{a}}$ \\
Well-watered (M) & $3.84 \pm 10.09^{\mathrm{a}}$ \\
Water-stressed (WSxM) &
\end{tabular}

Groups sharing a letter are not significantly different $(p<0.05)$ as determined by Kruskal Wallis test and Dunn's post-hoc test.

${ }^{\text {a }}$ Mean \pm S.D.

\section{Conclusions}

The research goals defined at the beginning of this paper assumed that biotic and/or abiotic factors applied during different development stages of plants can affect the proportions of chemical compounds differently, and that this ultimately affects the essential oil profile and fresh plant quality. This study contributed for the understanding of how production setting and ontogeny can alter the quality of a product with regards to the international norms and also how applying a sustainable method of production can be consistent with those standards.

The results obtained seem to suggest that AMF ameliorates the consequences of water stress, in terms of biomass while maintaining the demanded fresh plant (chemical) quality. Our results indicate that in terms of fresh plant quality for human consumption, the best practice is harvesting the plants during the flowering stage for the control or the other three treatments conditions. With regards to the use and quality of the essential oil of this genus, which is commercialized in Europe, Western Asia, and North America with high amounts of 1,8-cineole and linalool, plus smaller amounts of methyleugenol and eugenol (Simon et al., 1999), it is suggested that the flowering stage is also the optimal stage for this cultivar. This is due to the fact that linalool and 1,8-cineole presented a higher relative percentage and eugenol and methyleugenol registered a lower relative percentage in all the treatments and the control, and also because there is a more stable production of biomass by this stage. Furthermore, during the 2nd harvest, the EO samples from inoculated plants presented a slightly higher relative percentage of linalool (55\%) in comparison with the control (46\%) and also the relative percentage of 1,8-cineole did not vary in inoculated plants in comparison with the control EO samples. For this reason, the use of mycorrhizal fungi could well be of interest, since the EO samples from inoculated plants were not significantly different from the control samples and inoculated plants seem to produce more biomass. However, if the goal is to obtain an essential oil with a significant higher relative percentage of eugenol (for example for a particular pharmaceutical application), then the best harvest to carry is the 1st harvest (vegetative stage), with plants cultivated under water stress, without AMF. The main conclusion that can be drawn is that the application of AMF, together with water stress, enables obtaining equally good quality fresh plant material or essential oil during the flowering stage as the control condition, and also that water stress provokes the synthesis of a significantly different essential oil and fresh plant quality during the vegetative stage which can, from a commercial perspective, bring about 


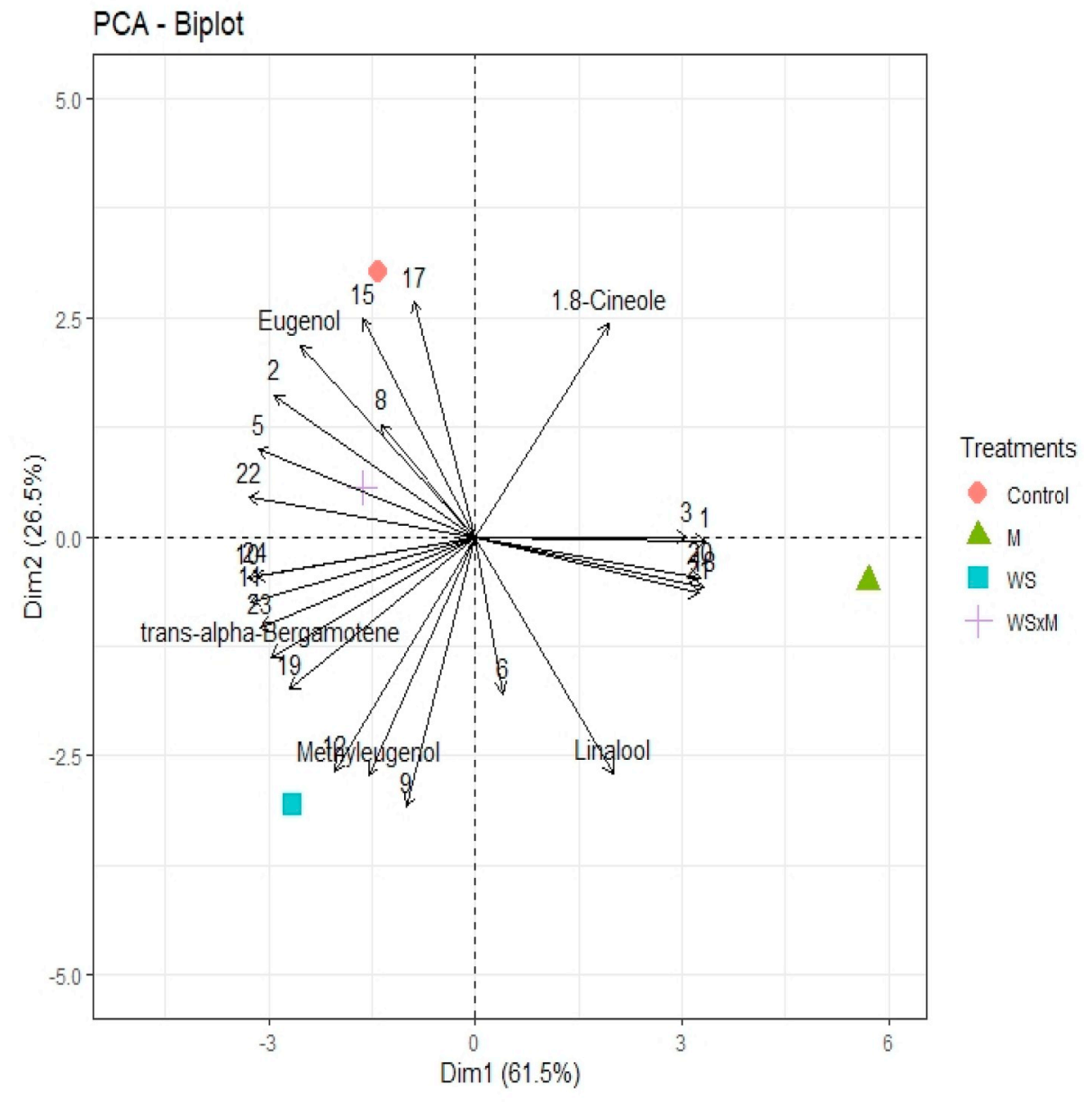

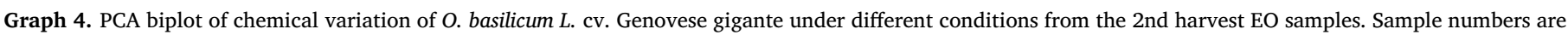

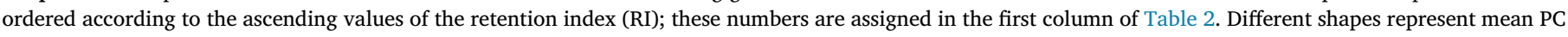
scores for treatments. Arrows are scaled vectors of the strongest loadings for individual chemical compounds on PC1 and PC2.

drawbacks with respect to the current end-uses.

Regardless, these findings should be replicated in a study where more replicas are used, and with proline concentration and the induction of defense gene expression in colonized roots data (to analyze the continuum of parasitism-mutualism between plant and AMF), together with the consideration of seasonal variations. Additionally, the availability of nutrients in the pot would enrich the analysis of the results. Pot confinement can lead to deficiency symptoms such as yellowing of leaves (specifically nitrogen), which, in turn, can influence the chemical profile of the essential oil. Likewise, shoot and root dry weight should also be included in future studies to bring about more assertive assumptions regarding the effect of AMF. Furthermore, investigating essential oils yield could prove important in terms of its economic relevance. However, some authors argue that the content of essential oils is more important than the yield, as content determines the market price for farmers and the marketability of fresh plants for different enduses (Ravindra and Kulkarni, 2015). Other authors argue that it is desirable to change the harvest season of certain aromatic plants to the phase after blooming in order to obtain better-quality oil, even at the cost of decreasing yield (Salgueiro et al., 2010).

Our data suggest that we still have a long way to go before we can obtain a closer understanding of the biosynthesis changes, whether constitutive or de novo, that are related to the factors applied during cultivation and also that integrated multiple-omics analysis is required to be able to better dissect the plant metabolic regulatory networks and their functions in the responses. The regulatory control is-among others-the most difficult aspect. In this regard, mechanisms controlling gene expression (such as transcription factors) and putative regulatory pathways should also be examined through pathway gene expression analysis in future studies.

On this basis, we conclude that the results of this study could be useful to improve predictions of organism responses to environmental change and also to provide tools to support sustainable plant production and management decisions. Our data indicates that stressor thresholds could be related to ontogeny - which is a result that casts a new light on the defense responses of MAP species. For this reason, refining ecological perspectives on plant behavior can be achieved by focusing decidedly on secondary metabolites. Finally, this study could well be of importance for not only the cultivation and quality control of the species used, but also for the selection of plants that have a significantly modified biochemical composition which could significantly contribute to the development of breeding programs in order to promote metabolite production and stress resistance.

\section{Funding}

Not applicable.

\section{Declaration of competing interest}

No competing interests to be declared. 


\section{References}

Aslani, Z., Hassani, A., Sadaghiyani, M.R., Sefidkon, F., Barin, M., 2011. Effect of two fungi species of arbuscular mycorrhizal (Glomus mosseae and Glomus intraradices) on growth, chlorophyll contents and P concentration in basil (Ocimum basilicum L.) under drought stress conditions. Iran. J. Med. Aromatic Plants 27 (3), 471-486 17350905.

Abbott, L., Robson, A., 1985. Formation of external hyphae in soil by four species of vesicular arbuscular mycorrhizal fungi. New Phytol. https://doi.org/10.1111/j.14698137.1985.tb03653.x.

Alandia, G., Jacobsen, S.-E., Kyvsgaard, N.C., Condori, B., Liu, F., 2016. Nitrogen sustains seed yield of quinoa under intermediate drought. J. Agron. Crop Sci. 202 (4), 281-291. https://doi.org/10.1111/jac.12155.

Atkinson, N.J., Urwin, P.E., 2012. The interaction of plant biotic and abiotic stresses: from genes to the field. J. Exp. Bot. 63 (10), 3523-3543. https://doi.org/10.1093/jxb/ ers100.

Augé, R.M., 2001. Water relations, drought and vesicular-arbuscular mycorrhizal symbiosis. Mycorrhiza 11, 3-42. https://doi.org/10.1007/s005720100097.

Barton, K.E., Boege, K., 2017. Future directions in the ontogeny of plant defense: understanding the evolutionary causes and consequences. Ecol. Lett. 20 (4), 403-411. https://doi.org/10.1111/ele.12744.

Bacchetta, G., Sánchez, A., Fenu, G., Jiménez-Alfaro, B., Mattana, E., Piotto, B., Virevaire, M., 2008. Conservación ex situ de plantas silvestres. Jardín Botánico Atlántico, Principado de Asturias. Book.

Bahreininejad, B.J., Razmjoo, B., Mirza, M., 2013. Influence of water stress on morphophysiological and phytochemical traits in Thymus daenensis. Int. J. Plant Prod. 7 (1), 151-166. https://doi.org/10.22069/ijpp.2012.927.

Bharti, N., Barnawal, D., Wasnik, K., Tewari, S.K., Kalra, A., 2016. Co-inoculation of Dietzia natronolimnaea and Glomus intraradices with vermicompost positively influences Ocimum basilicum L. growth and resident microbial community structure in salt affected low fertility soils. Appl. Soil Ecol. 100, 211-225. https://doi.org/10. 1016/j.apsoil.2016.01.003.

Berruti, A., Lumini, E., Balestrini, R., Bianciotto, V., 2016. Arbuscular mycorrhizal fungi as natural biofertilizers: let's benefit from past successes. Front. Microbiol. 6, 1559. https://doi.org/10.3389/fmicb.2015.01559.

Berta, G., Fusconi, A., Hooker, J.E., 2002. Arbuscular mycorrhizal modifications to plant root systems: scale, mechanisms and consequences. In: Gianinazzi, S., Schüepp, H., Barea, J.M., Haselwandter, K. (Eds.), Mycorrhizal Technology in Agriculture. From Genes to Bioproducts. Birkhaeuser, Basel, pp. 71-85.

Böhm, W., 1979. Methods of Studying Root Systems. Springer Science \& Business Media978-3-642-67282-8.

Boutra, T., Akhkha, A., Al-Shoaibi, A., Alhejeli, A., 2010. Effect of water stress on growth and water use efficiency (WUE) of some wheat cultivars (Triticum durum) grown in Saudi Arabia. J. Taibah Univ. Sci. 3 (1), 39-48. https://doi.org/10.1016/s16583655(12)60019-3.

Boccard, J., Veuthey, J.L., Rudaz, S., 2010. Knowledge discovery in metabolomics: an overview of MS data handling. J. Separ. Sci. 33 (3), 290-304. https://doi.org/10. 1002/jssc. 200900609.

Brundrett, M., Bougher, N., Dell, B., Grove, T., Malajczuk, N., 1996. Working with Mycorrhizas in Forestry and Agriculture. Australian Centre for International Agricultural Research. Book, pp. 179-183 (Chapter 4).2.

Caser, M., D'Angiolillo, F., Chitarra, W., Lovisolo, C., Ruffoni, B., Pistelli, L., Pistelli, L., Scariot, V., 2017. Ecophysiological and phytochemical responses of Salvia sinaloensis Fern. to drought stress. Plant Growth Regul. 84 (2), 383-394. https://doi.org/10. 1007/s10725-017-0349-1.

Caretto, S., Linsalata, V., Colella, G., Mita, G., Lattanzio, V., 2015. Carbon fluxes between primary metabolism and phenolic pathway in plant tissues under stress. Int. J. Mol. Sci. 16 (11), 26378-26394. https://doi.org/10.3390/ijms161125967.

Chaudhary, V., Kappor, R., Bhatnagar, A., 2008. Effectiveness of two arbuscular mycorrhizal fungi on concentrations of essential oil and artemisinin in three accessions of Artemisia annua L. J. Appl. Soil Ecol. 40 (1), 174-181. https://doi.org/10.1016/j. apsoil.2008.04.003.

Chaves, M.M., Pereira, J.S., Maroco, J., Rodriques, M.L., Ricardo, C.P.P., Osorio, M.L. Carvatho, I., Faria, T., Pinheiro, C., 2002. How plants cope with water stress in the field photosynthesis and growth? Ann. Bot. 89, 907-916 PMID: 12102516.

Chouhan, S., Sharma, K., Guleria, S., 2017. "Antimicrobial activity of some essential oils-present status and future perspectives". Medicines 4, 58. https://doi.org/10. 3390/medicines 4030058 .

Copetta, A., Lingua, G., Berta, G., 2006. Effects of three AM fungi on growth, distribution of glandular hairs, and essential oil production in Ocimum basilicum L. var. Genovese. Mycorrhiza 16, 485-494. https://doi.org/10.1007/s00572-006-0065-6.

Cornelissen, J.H.C., Lavorel, S., Garnier, E., Díaz, S., Buchmann, N., Gurvich, D.E., Poorter, H., 2003. A handbook of protocols for standardized and easy measurement of plant functional traits worldwide. Aust. J. Bot. 51 (4), 335. https://doi.org/10. 1071/bt02124.

Ekren, S., Sönmez, Ç., Özçakal, E., Kurttaş, Y.S.K., Bayram, E., Gürgülü, H., 2012. The effect of different irrigation water levels on yield and quality characteristics of purple basil (Ocimum basilicum L.). Agric. Water Manag. 109, 155-161. https://doi.org/10. 1016/j.agwat.2012.03.004.

Figueiredo, A., Barroso, J., Pedro, L., Scheffer, J., 2008. Factors affecting secondary metabolite production in plants: volatile components and essential oils. Flavour Fragrance J. 23 (4), 213-226. https://doi.org/10.1002/ffj.1875.

Flamini, G., Macchia, M., Benvenuti, S., 2006. Agronomic and phytochemical characteristics in some genotypes of Ocimum basilicum L. Acta Hortic. 723. https://doi. org/10.17660/ActaHortic.2006.723.15.
Grote, R., Sharma, M., Ghirardo, A., Schnitzler, J., 2019. A New Modeling Approach for Estimating Abiotic and Biotic Stress-Induced de novo Emissions of Biogenic Volatile Organic Compounds from Plants. Front. For. Glob. Change. https://doi.org/10.3389/ ffgc. 2019.00026.

Gheisari, S., Movahhedi, M., Salehi, A., Gholamhoseini, M., 2017. Responses of field grown fennel (Foeniculum vulgare Mill.) to different mycorrhiza species under varying intensities of drought stress. J. Appl. Res. Med. Aromatic Plants 5, 16-25. https://doi.org/10.1016/j.jarmap.2016.09.004.

Hazzoumi, Z., Moustakime, Y., Elharchli, E., Joutei, K., 2017. Effect of arbuscular mycorrhizal fungi (AMF) and water stress on growth, phenolic compounds, glandular hairs, and yield of essential oil in basil (Ocimum gratissimum L.). Chem. Biol. Technol. Agric. 2, 10. https://doi.org/10.1186/s40538-015-0035-3.

Havkin-Frenkel, D., Dudai, N., 2016. Biotechnology in Flavor Production, second ed. Wiley Blackwell. Technology \& Engineering.

Huang, Y.M., Zou, Y.N., Wu, Q.S., 2017. Alleviation of drought stress by mycorrhizas is related to increased root $\mathrm{H} 2 \mathrm{O} 2$ efflux in trifoliate orange. Sci. Rep. 7 (1). https://doi. org/10.1038/srep42335.

Iriti, M., Faoro, F., 2009. Chemical diversity and defence metabolism: how plants cope with pathogens and ozone pollution. Int. J. Mol. Sci. 10, 3371-3399. https://doi.org/ 10.3390/ijms10083371.

Iijima, Y., Davidovich-Rikanati, R., Fridman, E., Gang, D., Bar, E., Lewinsohn, E., Pichersky, E., 2004. The biochemical and molecular basis for the divergent patterns in the biosynthesis of terpenes and phenylpropenes in the peltate glands of three cultivars of basil. Plant Physiol. 136 (3), 3724-3736. https://doi.org/10.1104/pp 104.051318.

Jayne, B., Quigley, M., 2014. Influence of arbuscular mycorrhiza on growth and reproductive response of plants under water deficit: a meta-analysis. Mycorrhiza 24 (2). https://doi.org/10.1007/s00572-013-0515-x.

Johnson, N., Graham, J., Smith, F., 1997. Functioning of mycorrhizal associations along the mutualism-parasitism continuum. New Phytol. 135, 575-585. https://doi.org/10. 1046/j.1469-8137.1997.00729.x.

Kapoor, R., Anand, G., Gupta, P., Mandal, S., 2016. Insight into the mechanisms of enhanced production of valuable terpenoids by arbuscular mycorrhiza. Phytochemistry Rev. 16 (4), 677-692. https://doi.org/10.1007/s11101-016-9486-9.

Khakdan, F., Ranjbar, M., Nasiri, J., Ahmadi, F.S., Bagheri, A., Alizadeh, H., 2017. The relationship between antioxidant compounds contents and antioxidant enzymes under water-deficit stress in the three Iranian cultivars of basil (Ocimum basilicum L.). Acta Physiol. Plant. 38, 226. https://doi.org/10.1007/s11738-016-2241-4.

Kravitz, B., Guenther, A.B., Gu, L., Karl, T., Kaser, L., Pallardy, S.G., 2016. A new paradigm of quantifying ecosystem stress through chemical signatures. Ecosphere 7, e01559. https://doi.org/10.1002/ecs2.1559.

Kluge, M., 1976. Carbon and nitrogen metabolism under water stress. Water Plant Life 243-252. https://doi.org/10.1007/978-3-642-66429-8_15.

Labra, M., Miele, M., Ledda, B., Grassi, F., Mazzei, M., Sala, F., 2004. Morphological characterization, essential oil composition and DNA genotyping of Ocimum basilicum L. cultivars. Plant Sci. 167 (4), 725-731. https://doi.org/10.1016/j.plantsci.2004.04. 026.

Lange, B., Srividya, N., 2018. Enzymology of monoterpene functionalization in glandular trichomes. J. Exp. Bot. 70, 1095-1108. https://doi.org/10.1093/jxb/ery 436.

Lee, B.R., Kim, K.Y., Jung, W.J., Avice, J.C., Ourry, A., Kim, T.H., 2007. Peroxidases and lignification in relation to the intensity of water-deficit stress in white clover (Trifolium repens L.). J. Exp. Bot. 58, 1271-1279. https://doi.org/10.1093/jxb/ erl280.

Lee, E.H., Eo, J.K., Ka, K.H., Eom, A.H., 2013. Diversity of arbuscular mycorrhizal fungi and their roles in ecosystems. MYCOBIOLOGY 41 (3), 121-125. https://doi.org/10. 5941/myco.2013.41.3.121.

Lee, Y., Ding, P., 2016. Production of essential oil in plants: ontogeny, secretory structures and seasonal variations. PJSRR 2 (1), 1-10 ISSN: 2462-2028.

Lemberkovics, É., Nguyen, H., Tarr, K., Máthé, J.I., Petri, G., Vitányi, G., 1993. formation of biologically active substances of Ocimum basilicum L. During the vegetation period. Acta Hortic. 344, 334-346. https://doi.org/10.17660/actahortic.1993. 344.39.

Luna, M., Bekhradi, F., Ferreres, F., Jordán, M., Delshad, M., Gil, M., 2015. Effect of Water Stress and Storage time on anthocyanins and other phenolics of different genotypes of fresh sweet basil. J. Agric. Food Chem. 63 (42), 9223-9231. https://doi.org/10. 1021/acs.jafc.5b04131.

Manitto, P., Monti, D., Gramatica, P., 1974. Biosynthesis of phenylpropanoid compounds. Part I. Biosynthesis of eugenol in Ocimum basilicum L. J. Chem. Soc. 1727-1731. https://doi.org/10.1039/p19740001727.

Marotti, M., Piccaglia, R., Giovanelli, E., 1996. Differences in essential oil composition of basil (Ocimum basilicum L.) Italian cultivars related to morphological characteristics. J. Agric. Food Chem. 44 (12), 3926-3929. https://doi.org/10.1021/jf9601067.

Martin, F., Gianinazzi-Pearson, V., Hijri, M., Lammers, P., Requena, N., Sanders, I., Shachar-Hill, Y., Shapiro, H., Tuskan, G., Young, J., 2008. The long hard road to a completed Glomus intraradices genome. New Phytol. https://doi.org/10.1111/j. 1469-8137.2008.02671.x.

Makri, O., Kintzios, S., 2008. Ocimum sp. (basil): Botany, cultivation, pharmaceutical properties, and biotechnology. J. Herbs, Spices, Med. Plants 13 (3), 123-150. https:// doi.org/10.1300/j044v13n03 10.

Metlen, K.L., Aschehoug, E.T., Callaway, R.M., 2009. Plant behavioral ecology: dynamic plasticity in secondary metabolites. Plant Cell Environ. 32 (6), 641-653. https://doi. org/10.1111/j.1365-3040.2008.01910.x.

Miele, M., Dondero, R., Ciarallo, G., Mazzei, M., 2001a. Methyleugenol in Ocimum basilicum L. Cv. Genovese gigante. J. Agric. Food Chem. 49, 517-521. https://doi.org/ 10.1021/jf000865w.

Miele, M., Ledda, B., Falugi, C., Mazzei, M., 2001b. Methyleugenol and eugenol variation 
in Ocimum basilicum cv. Genovese gigante grown in greenhouse and in vitro. Bollettino della Società italiana di biologia sperimentale 77 (4-6), 43-50.

Miller, R.E., Gleadow, R.M., Cavagnaro, T.R., 2014. Age versus stage: does ontogeny modify the effect of phosphorus and arbuscular mycorrhizas on above- and belowground defense in forage sorghum? Plant Cell Environ. 37 (4), 929-942. https://doi. org/10.1111/pce.12209.

Mondello, L., Zappia, G., Cotroneo, A., Bonaccorsi, I., Chowdhury, J.U., Yusuf, M., Dugo, G., 2002. Studies on the essential oil-bearing plants of Bangladesh. Part VIII. Composition of some Ocimum oils: O. basilicum L. var. purpurascens; O. sanctum L. green; O. sanctum L. purple; O. americanum L., citral type; O. americanum L., camphor type. Flavour Fragrance J. 17 (5), 335-340. https://doi.org/10.1002/ffj. 1108.

McKey, D., 1979. The distribution of secondary compounds within plants. In: Rosenthal, G.A., Janzen, D.H. (Eds.), Herbivores: Their Interaction with Secondary Plant Metabolites. Academic Press, New York, pp. 55-133.

Nurzyńska-Wierdak, R., Bogucka-Kocka, A., Kowalski, R., Borowski, B., 2012. Changes in the chemical composition of the essential oil of sweet basil (Ocimum basilicum L.) depending on the plant growth stage. Chemija 23 (3), 216-222. https://doi.org/10. 3906/tar-1203-43.

Oehl, F., Laczko, E., Bogenrieder, A., Stahr, K., Bosch, R., Heijden, M., Sieverding, E., 2010. Soil type and land use intensity determine the composition of arbuscular mycorrhizal fungal communities. Soil Biol. Biochem. https://doi.org/10.1016/j. soilbio.

Padalia, R.C., Verma, R.S., Chauhan, A., Chanotiya, C.S., 2013. Changes in aroma profiles of 11 Indian Ocimum taxa during plant ontogeny. Acta Physiol. Plant. 35 (8), 2567-2587. https://doi.org/10.1007/s11738-013-1293-y.

Polcyn, W., Paluch-Lubawa, E., Lehmann, T., Mikuła, R., 2019. Arbuscular mycorrhiza in highly fertilized maize cultures alleviates short-term drought effects but does not improve fodder yield and quality. Front. Plant Sci. 10. https://doi.org/10.3389/fpls. 2019.00496.

Purkayastha, J., Nath, S.C., 2006. Composition of the camphor-rich essential oil of Ocimum basilicum L. Native to Northeast India. J. Essent. Oil Res. 18 (3), 332-334. https://doi.org/10.1080/10412905.2006.9699104.

Ravindra, N.S., Kulkarni, R.N., 2015. Essential oil yield and quality in rose-scented geranium: variation among clones and plant parts. Sci. Hortic. 184, 31-35. https://doi. org/10.1016/j.scienta.2014.12.023.

Rakic, Z., Johnson, C.B., 2002. Influence of environmental factors (including UV-B radiation) on the composition of the essential oil of Ocimum basilicum L.-Sweet basil. J. Herbs, Spices, Med. Plants 9 (2-3), 157-162. https://doi.org/10.1300/ j044v09n02 22.

Raguso, R.A., Pichersky, E., 1999. New Perspectives in Pollination Biology: flora Fragrances. A day in the life of a linalool molecule: chemical communication in a plant-pollinator system. Part 1: linalool biosynthesis in flowering plants. Plant Species Biol. 14 (2), 95-120. https://doi.org/10.1046/j.1442-1984.1999.00014.x.

Rasouli-Sadaghiani, M., Hassani, A., Barin, M., Danesh, Y., Sefidkon, F., 2010. Effects of arbuscular mycorrhizal (AM) fungi on growth, essential oil production and nutrients uptake in basil. J. Med. Plants Res. 4 (21), 2222-2228. https://doi.org/10.5897/ JMPR10.337.

Renu, I.K., Haque, I., Kumar, M., Poddar, R., Bandopadhyay, R., Rai, A., Mukhopadhyay, K., 2014. Characterization and functional analysis of eugenol O-methyltransferase gene reveal metabolite shifts, chemotype specific differential expression and developmental regulation in Ocimum tenuiflorum L. Mol. Biol. Rep. 41 (3), 1857-1870. https://doi.org/10.1007/s11033-014-3035-7.

Ruiz-Lozano, J.M., Azcon, R., Gomez, M., 2005. Effects of arbuscular-mycorrhizal glomus species on drought tolerance: physiological and nutritional plant responses. Appl. Environ. Microbiol. 61 (2), 456-460. https://doi.org/10.1128/aem.61.2.456-460. 1995. https://search.crossref.org/?q=Effects + of + arbuscular-mycorrhizal + glomus + species + on + drought + tolerance $\% 3 \mathrm{~A}+$ physiological + and + nutritional + plant + responses.

Ronsheim, M.L., 2012. The effect of mycorrhizae on plant growth and reproduction varies with soil phosphorus and developmental stage. Am. Midl. Nat. 167 (1), 28-39. https://doi.org/10.1674/0003-0031-167.1.28.

Roque, R., 1991. Composição do óleo essencial de Ocimum basilicum L. cultivado. Bol. Fac. Farm. Coimbra (Coimbra) 15, 47-51. https://doi.org/10.1590/1983-084X/14 031.

Salgueiro, L., Martins, A.P., Correia, H., 2010. Raw materials: the importance of quality and safety. A review. Flavour Fragrance J. 25, 253-271. https://doi.org/10.1002/ffj. 1973.

Salekdeh, G.H., Siopongco, J., Wade, L.J., Ghareyazie, B., Bennett, J., 2002. Proteomic analysis of rice leaves during drought stress and recovery. Proteomics 2 (9), 1131-1145. https://doi.org/10.1002/1615-98611. 10.1002/ffj .1973.

Selmar, D., Kleinwachter, M., 2013. Stress enhances the synthesis of secondary plant products: the impact of stress-related over-reduction on the accumulation of natural products. Plant Cell Physiol. 54 (6), 817-826. https://doi.org/10.1093/pcp/pct054.

Simon, J.E., Reiss-Bubenheim, D., Joly, R.J., Charles, D.J., 1992. Water stress-induced alterations in essential oil content and composition of sweet basil. J. Essent. Oil Res. 4 (1), 71-75. https://doi.org/10.1080/10412905.1992.9698013.

Simon, J.E., Morales, M.R., Pippen, W.B., Vieira, R.F., Hao, Z., 1999. Basil, a source of aroma compounds and a popular culinary and ornamental herb. In: Janick, J. (Ed.), Perspectives on New Crops and New Uses. ASHS Press, Alexandria, VA, pp. 499-505.

Smith, S., Read, D., 1997. Mycorrhizal Symbiosis, second ed. Academic Press978-0-12652840-4https://doi.org/10.1016/B978-0-12-652840-4.X5000-1.

Smith, S., Read, D., 2008. Mycorrhizal Symbiosis, third ed. Academic Presshttps://doi. org/10.1016/B978-0-12-652840-4.X5000-2. ISBN 978-0-15-652840-4.

Sorial, M.E., El-Gamal, S.M., Gendy, A.A., 2010. Response of sweet basil to jasmonic acid application in relation to different water supplies. Biosci. Res. 7 (1), 39-47 ref.42. ISSN:1811-9506.

Shulaev, V., Cortes, D., Miller, G., Mittler, R., 2008. Metabolomics for plant stress response. Physiol. Plantarum 132 (2), 199-208. https://doi.org/10.1111/j.1399-3054. 2007.01025.x.

Sun, X., Shi, J., Ding, G., 2017. Combined effects of arbuscular mycorrhiza and drought stress on plant growth and mortality of forage sorghum. Appl. Soil Ecol. 119, 384-391. https://doi.org/10.1016/j.apsoil.2017.07.030.

Tawaraya, K., 2003. Arbuscular mycorrhizal dependency of different plant species and cultivars. Soil Sci. Plant Nutr. 49 (5), 655-668. https://doi.org/10.1080/00380768. 2003.10410323.

Tarchoune, I., Sgherric, C., Izzo, R., Lachaal, M., Ouerghi, Z., Navari-Izzo, F., 2010. Antioxidative response of Ocimum basilicum L. to sodium chloride and sodium sulphate salinization. Plant Physiol. Biochem. 48, 772-777. https://doi.org/10.1016/j. plaphy.2010.05.006.

Telci, I., Bayram, E., Yılmaz, G., Avcı, B., 2006. Variability in essential oil composition of Turkish basils (Ocimum basilicum L.). Biochem. Systemat. Ecol. 34 (6), 489-497. https://doi.org/10.1016/j.bse.2006.01.009.

Toncer, O., Karaman, S., Diraz, E., Tansi, S., 2017. Essential oil composition of Ocimum basilicum L. At different phenological stages in semi-arid environmental conditions. Fresenius Environ. Bull. 26 (No. 8/2017), 5441-5446.

Volpin, H., Elkind, Y., Okon, Y., Kapulnik, Y., 1994. A vesicular arbuscular mycorrhizal fungus (Glomus intraradices) induces a defense response in alfalfa roots. Plant Physiol. 104, 683-689. https://doi.org/10.1104/pp.104.2.683.

Wang, X., Cai, X., Xu, C., Wang, Q., Dai, S., 2016. Drought-responsive mechanisms in plant leaves revealed by proteomics. Int. J. Mol. Sci. 17 (10), 1706. https://doi.org/ 10.3390/ijms17101706.

Winkel, T., Payne, W., Renno, J.F., 2001. Ontogeny modifies the effects of water stress on stomatal control, leaf area duration and biomass partitioning of Pennisetum glaucum. New Phytol. 149 (1), 71-82. https://doi.org/10.1046/j.1469-8137.2001.00008.x.

Xavier, L.J.C., Boyetchko, S.M., 2002. Arbuscular mycorrhizal fungi as biostimulants and bioprotectants of crops. Appl. Mycol. Biotechnol. 2, 311-340. https://doi.org/10. 1016/s1874-5334(02)80015-6.

Xie, Z., Kapteyn, J., Gang, D., 2008. A systems biology investigation of the MEP/terpenoid and shikimate/phenylpropanoid pathways points to multiple levels of metabolic control in sweet basil glandular trichomes. Plant J. 54 (3), 349-361. https://doi.org/ 10.1111/j.1365-313X.2008.03429.x.

Yayi, E., Moudachirou, M., Chalchat, J.C., 2001. Chemotyping of three Ocimum species from Benin: O. Basilicum, O. Canum and O. Gratissimum. J. Essent. Oil Res. 13 (1), 13-17. https://doi.org/10.1080/10412905.2001.9699590.

Yordanov, I., Velikova, V., Tsonev, T., 2000. Plant responses to drought, acclimation and stress tolerance. Photosynthetica 38 (2), 171-186. https://doi.org/10.1023/ a:1007201411474.

Zeng, Y., Guo, L., Chen, B., Hao, Z., Wang, J., Huang, L., Yang, G., Cui, X., Yang, L., Wu, Z., Chen, M., Zhang, Y., 2013. Arbuscular mycorrhizal symbiosis and active ingredients of medicinal plants: current research status and prospectives. Mycorrhiza 23 (4), 253-265. https://doi.org/10.1007/s00572-013-0484-0. 